PALABRAS CLAVE

Tratados

Libre comercio

Exportaciones

Importaciones

Estadísticas comerciales

ASEAN

ALADI

América Latina

China

India
Comercio internacional

Relaciones económicas internacionales

REVISTA DE LA CEPAL 93 - DICIEMBRE 2007

\section{América Latina al encuentro de China e India: perspectivas y desafíos en comercio e inversión}

\author{
Osvaldo Rosales y Mikio Kuwayama
}

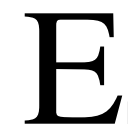

I alto crecimiento pronosticado para China e India mantendría a estos países como el polo más importante de la economía mundial en los próximos años, ofreciendo a América Latina y el Caribe un mercado de gran potencial para sus productos de exportación. Esta posibilidad ha sido poco explotada hasta ahora, salvo en el caso de algunos sectores de productos primarios provenientes de América del Sur. América Latina debería fortalecer los vínculos con ambos países asiáticos, buscando una mayor complementariedad productiva con ellos y estableciendo acuerdos comerciales y además alianzas de comercio y de inversión, lo que le daría nuevo acceso a esos dos mercados y

\section{Osvaldo Rosales}

Director de la División de Comercio Internacional e Integración,

CEPAL

osvaldo.rosales@cepal.org

Mikio Kuwayama,

Jefe de la Unidad de Comercio Internacional,

CEPAL

- mikio.kuwayama@cepal.org propiciaría su incorporación a las cadenas asiáticas de producción y exportación. 


\section{Introducción}

Asia es la región más dinámica en la economía mundial en términos de crecimiento, comercio internacional, inversión extranjera directa, innovación tecnológica y fuente de recursos financieros para mantener los equilibrios internacionales. Una característica importante de este surgimiento de Asia como uno de los ejes de la economía mundial es la irrupción de China e India como actores principales, en torno a los cuales se articula un reordenamiento económico y comercial que es el de mayor envergadura en Asia. También se detecta un interés sin precedentes de ambos países asiáticos por establecer relaciones estratégicas con América Latina y el Caribe. Dado el alto crecimiento que se ha pronosticado para China e India, estos países seguirían siendo el polo más importante del crecimiento mundial en los próximos años, lo que a su vez ofrecería a la región latinoamericana un mercado de gran potencial para sus productos de exportación. Esta posibilidad ha sido poco explotada hasta ahora, salvo en el caso de algunos sectores de productos primarios.

\section{II}

\section{Principales características y desempeño económico y comercial}

\section{China e India confirman tendencia al crecimiento acelerado}

En los últimos años, China ha acrecentado considerablemente su peso en la economía mundial. En términos del producto interno bruto (PIB), medido a precios corrientes, la economía china se convirtió en la cuarta del mundo en 2005, después de los Estados Unidos, Japón y Alemania, y ha superado ya al Reino Unido y Francia. Si la medición del PIB se hace en moneda de paridad de poder adquisitivo (PPA), aparece como la segunda economía mundial después de los Estados Unidos. China por sí sola generó en el 2005 más de $27 \%$ del crecimiento del PIB mundial en términos de paridad de poder adquisitivo. Este porcentaje está por encima de la contribución conjunta de los Estados Unidos, la Unión Europea y Japón (CEPAL, 2006) y es un aporte innegable al mantenimiento de la tasa global. La economía china creció $10,7 \%$ en el 2006, gracias al dinamismo de la inversión interna y las exportaciones, ratificando así un promedio cercano a los dos dígitos a lo largo de tres décadas. Durante este período, el sector industrial ha

$\square$ Los errores u omisiones son de exclusiva responsabilidad de los autores. Estos agradecen la asistencia estadística de José Durán, José Carlos Mattos y Jaime Contador. sido el motor del crecimiento y se ha incrementado la participación de los servicios en el PIB, en tanto que la agricultura ha retrocedido (cuadro 1). El dinamismo del sector exportador chino también se refleja en un favorable comportamiento del superávit de cuenta corriente.

Por su parte, India exhibió un crecimiento de 9,2\% en el 2006, con una expansión del consumo de nivel similar. En 1991 se comenzó a aplicar un nuevo programa económico - cuyos pilares han sido el fomento de la liberalización económica y la corrección de los desequilibrios macroeconómicos- que permitió que el país alcanzara un crecimiento anual medio de 6,4\% entre 1995 y el 2005. La economía de India ha estado marcada por un gran cambio estructural: la participación de los servicios en el PIB aumentó, mientras disminuía claramente la del sector agrícola (cuadro 1). Se proyecta que el país mantendrá su ritmo de crecimiento en los próximos años y que el sector de los servicios seguirá siendo el motor del desarrollo económico. En cuanto al sector manufacturero, su papel en India es menos dominante que en China y su aumento de productividad mucho menos pronunciado (UNCTAD, 2005). La inflación, una preocupación permanente en India, es cercana al 6\%, a pesar del alza de los precios del petróleo. A diferencia de China, en India ha sido deficitaria la posición de cuenta corriente en los últimos años. 
CUADRO 1

China e India: principales indicadores de la producción y el comercio

\begin{tabular}{|c|c|c|c|c|c|c|}
\hline \multirow{2}{*}{$\begin{array}{l}\text { Indicadores } \\
\text { Población (miles de habitantes, 2005) }\end{array}$} & \multicolumn{3}{|c|}{ China } & \multicolumn{3}{|c|}{ India } \\
\hline & \multicolumn{3}{|c|}{1304500} & \multirow{2}{*}{\multicolumn{3}{|c|}{$\begin{array}{r}1094583 \\
785468\end{array}$}} \\
\hline PIB (millones de dólares corrientes, 2005) & \multicolumn{3}{|c|}{2228862} & & & \\
\hline PIB (millones de dólares corrientes a paridad de poder adquisitivo, 2005) & \multicolumn{3}{|c|}{8572666} & \multicolumn{3}{|c|}{3815553} \\
\hline PIB real (variación porcentual real, 1995-2005) & \multicolumn{3}{|c|}{9,2} & \multicolumn{3}{|c|}{6,4} \\
\hline Composición del PIB por actividades (\%) & 1985 & 1995 & 2005 & 1985 & 1995 & 2005 \\
\hline Agricultura & 28,4 & 19,8 & 12,5 & 33,7 & 28,2 & 18,6 \\
\hline Industria & 43,1 & 47,2 & 47,3 & 26,4 & 28,1 & 28,6 \\
\hline \multirow[t]{2}{*}{ Servicios } & 28,5 & 33,1 & 40,3 & 39,9 & 43,6 & 53,8 \\
\hline & 100,0 & 100,0 & 100,0 & 100,0 & 100,0 & 100,0 \\
\hline Saldo en cuenta corriente, (miles de millones de dólares, 2005) & \multicolumn{3}{|r|}{160,8} & \multicolumn{3}{|r|}{$-11,9$} \\
\hline Cuenta corriente (como porcentaje del PIB, 2005) & \multicolumn{3}{|r|}{7,2} & \multicolumn{3}{|r|}{$-1,5$} \\
\hline Comercio per cápita (millones de dólares, 2003-2005) & \multicolumn{3}{|r|}{962} & \multicolumn{3}{|r|}{236} \\
\hline Relación entre el comercio y el PIB (\%) & \multicolumn{3}{|r|}{64,5} & \multicolumn{3}{|r|}{36,7} \\
\hline Exportaciones de bienes y servicios, variación anual $(\%, 1995-2005)$ & \multicolumn{3}{|r|}{19} & \multicolumn{3}{|r|}{14} \\
\hline Importaciones de bienes y servicios, variación anual $(\%, 1995-2005)$ & \multicolumn{3}{|r|}{16} & \multicolumn{3}{|r|}{12} \\
\hline
\end{tabular}

Exportaciones de mercancías f.o.b. (millones de dólares, 2005) Principales destinos de las exportaciones

Importaciones de mercancías C.I.F. (millones de dólares, 2005)

Principales orígenes de las importaciones
761954

Estados Unidos (21,4\%); UE-25 (18,9\%); Hong Kong, China (16,3\%); Japón (11,0\%); Corea, Rep. de $(4,6 \%)$
95096

UE-25 (21,5\%); Estados Unidos $(16,5 \%)$; Emiratos Árabes Unidos $(8,8 \%)$; China $(6,6 \%)$; Singapur $(4,8 \%)$

660003

Japón (15,2\%); Rep, de Corea $(11,6 \%)$; prov. china de Taiwán $(11,3 \%)$; UE-25 (11,2\%); China $(8,4 \%)$

\begin{tabular}{|c|c|c|c|c|}
\hline Exportaciones de servicios comerciales (millones de dólares, 2005), & \multicolumn{3}{|c|}{73909} & 56096 \\
\hline Transporte & \multicolumn{3}{|c|}{20,9} & 10,4 \\
\hline Viajes & \multicolumn{3}{|c|}{39,6} & 11,4 \\
\hline Otros servicios comerciales & \multicolumn{3}{|c|}{39,5} & 78,1 \\
\hline $\begin{array}{l}\text { Importaciones de servicios comerciales (millones de dólares, 2005), } \\
\text { por principales partidas de servicios (\%) }\end{array}$ & \multicolumn{3}{|c|}{87173} & 52211 \\
\hline Transporte & \multicolumn{3}{|c|}{34,2} & 38,0 \\
\hline Viajes & \multicolumn{3}{|c|}{26,2} & 11,1 \\
\hline Otros servicios comerciales & \multicolumn{3}{|c|}{39,6} & 50,9 \\
\hline Cobertura de consolidación arancelaria & \multicolumn{3}{|c|}{$100,0(2010)$} & $73,8(2005)$ \\
\hline Aranceles (nación más favorecida) & $\begin{array}{l}\text { Consolidados } \\
\text { finales }\end{array}$ & $\begin{array}{l}\text { Aplicados } \\
\quad 2005\end{array}$ & $\begin{array}{l}\text { Consolidados } \\
\text { finales }\end{array}$ & $\begin{array}{l}\text { Aplicados } \\
\quad 2005\end{array}$ \\
\hline \multicolumn{5}{|l|}{ Promedio simple de los derechos ad valorem (\%) } \\
\hline Todos los productos & 10,0 & 10,0 & 49,8 & 18,3 \\
\hline Productos agropecuarios (Acuerdo sobre la agricultura, ASA) & 15,8 & 15,9 & 114,5 & 37,6 \\
\hline Productos no agropecuarios & 9,1 & 9,1 & 34,3 & 15,4 \\
\hline Derechos no ad valorem (\% del total de líneas arancelarias) & 0,0 & 0,4 & 7,2 & 0,0 \\
\hline \multicolumn{5}{|l|}{$\begin{array}{l}\text { Importaciones en régimen de franquicia arancelaria } \\
\text { (nación más favorecida) }\end{array}$} \\
\hline Proporción de las importaciones totales, 2003 & & $34,0(2003)$ & & $2,1(2001)$ \\
\hline $\begin{array}{l}\text { Entradas de inversión extranjera directa (millones de dólares, saldo balan- } \\
\text { za de pagos, promedio anual 1995-2004) }\end{array}$ & & 44316 & & 3755 \\
\hline Inflación (variación anual, 1995-2005) & & 3,3 & & 6,8 \\
\hline Coeficiente de Gini (1996-2002) & & 44,7 & & 32,5 \\
\hline
\end{tabular}

134831

UE-25-(17,1\%); Estados Unidos (6,3\%); China (6,2\%); Suiza (5,3\%); Emiratos Árabes Unidos (4,2\%) 


\section{Papel cada vez mayor de China en el mante- nimiento de los equilibrios macroeconómicos mundiales}

El protagonismo de China es más que evidente no solo en la producción y el comercio mundial sino también en el ámbito financiero global. El país desempeña un papel cada vez más importante en la mantención de equilibrios económicos globales. Su oferta abundante y barata contribuye a una demanda elevada pero con baja inflación en los países desarrollados, provee de ahorros baratos a los Estados Unidos, manteniendo baja la tasa de interés y acumula reservas mediante la compra de bonos del Tesoro, ayudando así a financiar el déficit en cuenta corriente estadounidense. ${ }^{1}$ Por ende, cualquier indicio de lo que China podría hacer con sus enormes reservas tiene inmediatas repercusiones en los mercados financieros internacionales. En cambio, el papel que desempeña India en el ámbito financiero internacional es mucho menor. ${ }^{2}$

Los desequilibrios comerciales en el mundo continúan agravándose. En efecto, el déficit en cuenta corriente de los Estados Unidos creció hasta llegar a 856.700 millones de dólares a fines del 2006, equivalente al 6,5\% del PIB. De ese aumento, el 63\% se atribuye al incremento de las importaciones desde China: el déficit en cuenta corriente de los Estados Unidos con China subió de 220.100 millones de dólares a 261.700 millones. El enorme déficit de cuenta corriente de Estados Unidos se compensa globalmente por los superávit crecientes de los países emergentes asiáticos, sobre todo China, ${ }^{3}$ de los exportadores de petróleo y también de los países latinoamericanos y caribeños, responsables estos últimos por casi $14 \%$ del déficit estadounidense en 2005. Estados Unidos mantuvo un déficit de cuenta corriente con India por una suma cercana a los 12.000 millones de dólares tanto en el 2005 como en el 2006.

La evolución de la moneda china, el yuan, en el 2006 contribuyó poco a facilitar el proceso de ajuste

\footnotetext{
${ }^{1}$ En diciembre del 2006, China tenía en su poder valores del Tesoro estadounidense por el equivalente a 350.000 millones de dólares, más de la mitad de lo que mantenía Japón (644.000 millones de dólares). A su vez, en esa fecha, las reservas de China sobrepasaron los 1.066.000 millones de dólares, cifra superior a la de Japón (875.000 millones). Las reservas chinas equivalen a más de $40 \%$ del PIB.

${ }^{2}$ A fines del 2006, el Banco de Reserva de India tenía reservas por 177.000 millones de dólares y solo 14.000 millones en bonos del Tesoro estadounidense.

${ }^{3}$ China se ha transformado en un importante socio comercial de los Estados Unidos, al punto de que en el 2005 China suministraba el $14,6 \%$ de las importaciones totales de los Estados Unidos, mientras India solo el 3,2\%.
}

de los desequilibrios externos de los Estados Unidos. Después de que se flexibilizara el tipo de cambio del yuan en julio del 2005, esta moneda se apreció $7 \%$ hasta agosto del 2007. Las consecuencias de una revaluación sustancial del yuan no pueden predecirse con certeza. En todo caso, la revaluación del tipo de cambio de China y de la mayoría del resto de los países de Asia no sería suficiente para estabilizar el desequilibrio comercial de los Estados Unidos en un rango sostenible. Las autoridades estadounidenses siguen presionando al gobierno chino para que flexibilice más su régimen cambiario y hay iniciativas legislativas que contemplan algunas medidas de represalia en el caso de que esto no se haga. En India, la rupia ha seguido muy de cerca la tendencia de los mercados financieros internacionales: en términos reales ponderados por las respectivas monedas, se sitúa $6 \%$ por encima del promedio de los últimos quince años; si se mantiene la creciente tendencia deficitaria en cuenta corriente, el tipo de cambio real podría depreciarse.

\section{Protagonismo de China e India en el comercio mundial}

En el 2006 las exportaciones de mercancías de China e India en su conjunto constituyeron el 9,2\% del total mundial (habiendo sido de 4,5\% en el 2000). Por su parte, las exportaciones chinas crecieron un $27 \%$, alcanzando a 969.000 millones de dólares, monto que equivale a cerca de 1,5 veces las exportaciones de América Latina y el Caribe. Por otra parte, en el mismo año 2006 las exportaciones e importaciones de mercancías de India ascendieron a 120 mil millones y 174 mil millones de dólares, respectivamente.

Tanto para China como para India, los Estados Unidos y la Unión Europea son un muy importante mercado de exportación (cuadro 1). Por lo demás, las cuotas de mercado que tienen los vecinos del AsiaPacífico en el comercio chino son muy elevadas; en este sentido destacan en particular la Región Administrativa Especial de Hong Kong, China, y la provincia china de Taiwán, así como Japón, la República de Corea y los países de la Asociación de Naciones del Asia Sudoriental (ASEAN). Como se verá más adelante, de esta forma China se está convirtiendo para muchos vecinos asiáticos en una plataforma para exportar a los mercados estadounidense y europeo. De manera similar, esos países asiáticos se han convertido en mercados de alta importancia para India: Asia y Oceanía en conjunto representaron cerca de 35\% tanto de las exportaciones como de las importaciones totales de India durante 
el año fiscal 2005/2006. Además, África occidental y el Oriente Medio son importantes mercados para productos indios. La participación de América Latina y el Caribe en el comercio de los dos países asiáticos examinados es de solo $3 \%$.

China e India figuran entre los diez mayores exportadores e importadores de servicios comerciales. Sobresale el dinamismo de las exportaciones de servicios de India, las que a partir del 2003 han crecido a más del doble de las exportaciones de China, acercándose rápidamente al nivel de este país y al de América Latina y el Caribe. El componente de "otros servicios comerciales", que incluye los subsectores de más alto crecimiento mundial (por ejemplo, los servicios de comunicaciones, construcción, seguros, informática e información, las regalías y derechos de licencia, los servicios personales, culturales y recreativos, y otros servicios empresariales), representa $78 \%$ de las exportaciones de servicios comerciales de India, superando con creces el peso relativo de otros dos principales componentes de los servicios, que son el transporte y los viajes (cuadro 1). Para China, el componente "otros servicios comerciales" alcanzó a 292.000 millones de dólares en el 2005, equivalentes al 40\% del total de los servicios exportados por este país.

El dinamismo de India en servicios comerciales complejos guarda estrecha relación con su estrategia de inserción internacional, la que privilegia actividades basadas en las tecnologías de la información y de las comunicaciones (TIC) y en la externalización de procesos empresariales. Estos dos subsectores están fuertemente orientados a las exportaciones y muestran buenos resultados gracias a la creciente demanda de mano de obra barata pero calificada y con manejo del idioma inglés, al aprovechamiento de la diferencia horaria con el hemisferio norte y a la instalación de una red de fibra óptica bajo el océano. En el período 2004-2005 India representó el 65\% del mercado global de servicios comerciales en materia de tecnologías de la información y de las comunicaciones y el $46 \%$ del de externalizaciones de procesos empresariales (Gobierno de India, 2006, p. 117).

\section{China e India como principales demandantes de productos primarios y manufacturados de interés para América Latina}

El aporte excepcional de China al presente ciclo de recuperación mundial ha generado importantes efectos globales, convirtiéndose este país en un importante consumidor de materias primas, minerales, energía y, en alguna medida, también de alimentos y productos industriales. China ocupa el primer lugar como consumidor mundial de carbón, estaño, zinc, cobre y cereales, y un lugar destacado en los casos de fertilizantes, hierro y acero, banano, granos oleaginosos y aceites, plásticos, equipamiento electrónico, aparatos ópticos, fotográficos y médicos, reactores nucleares y maquinaria. En ocho de 15 productos seleccionados el consumo de China equivale al 20\% o más del consumo mundial, en 10 China es un demandante neto en los mercados mundiales, y en 14 es uno de los tres principales consumidores mundiales (cuadro 2). Esto ha significado presiones sobre los mercados internacionales y considerables alzas de precios de muchos productos. Tal es el caso del cobre, la soja, el níquel y el petróleo, cuyos precios aumentaron más que los de las manufacturas.

En cuanto a productos manufactureros, China e India desempeñan un papel relevante, si bien mucho mayor en el caso de China. Estos dos países han sido determinantes como consumidores de varios productos manufactureros cuyo comercio ha sido muy dinámico en la última década. La Organización de Comercio Exterior de Japón (JETRO, 2006) indica que el mercado mundial de automóviles se expandió en 7 millones de unidades entre 1999 y el 2005, y que casi $46 \%$ de esa expansión correspondió al mercado chino y 7,4\% al indio. También se observan porcentajes muy elevados en otros bienes de alta tecnología, como ventas de artículos electrónicos y acceso a teléfonos celulares y computadores portátiles. En los dos primeros, la demanda de consumo de China superó a la de los Estados Unidos.

La estructura exportadora de China ha cambiado de manera espectacular en las últimas dos décadas. De ser un país exportador de petróleo crudo y refinado y de prendas de vestir, pasó a ser un exportador de productos electrónicos y de tecnología de la información y de las comunicaciones. Sin embargo, esta transformación no significa necesariamente que China se haya convertido en uno de los principales países productores y exportadores de tales productos. Como indican Branstetter y Lardy (2006), la mayoría de ellos se han ido transformando en cuasi commodities de alta venta (equipos de DVD, computadoras portátiles y teléfonos celulares). Además, para que estos sectores dinámicos expandan sus exportaciones se precisan altos niveles de insumos importados, por lo cual el valor agregado local es poco y representa solo $15 \%$ del valor exportado por el sector electrónico y el de las Tic. En estos productos, China sigue especializándose en ensamblajes, cuyos procesos de producción hacen uso intensivo de mano de obra. 


\begin{tabular}{|c|c|c|c|c|c|c|}
\hline & Producción & Consumo & Importaciones & Exportaciones & $\begin{array}{c}\text { Coeficiente } \\
\text { consumo/producción }\end{array}$ & $\begin{array}{c}\text { Posición en el } \\
\text { consumo mundial }\end{array}$ \\
\hline Carbón & 35,0 & 35,6 & 71,7 & 0,0 & 103,4 & 1 \\
\hline Mineral de hierro & 20,7 & 32,8 & 25,0 & 0,0 & 158,5 & 1 \\
\hline Acero & 25,8 & 22,5 & 2,5 & 13,1 & 87,2 & 1 \\
\hline Estaño & 37,1 & 27,6 & 0,0 & 13,5 & 40,4 & 1 \\
\hline Zinc & 23,6 & 25,9 & 6,8 & 13,0 & 56,1 & 1 \\
\hline Aluminio & 22,8 & 21,0 & 5,6 & $\ldots$ & 90,5 & 2 \\
\hline Plomo & 19,6 & 19,6 & 2,5 & 27,2 & 78,3 & 2 \\
\hline Cobre & 12,9 & 19,6 & 25,3 & 0,0 & 157,3 & 1 \\
\hline Soja & 8,1 & 17,4 & 35,4 & 0,4 & 165,6 & 2 \\
\hline Cereales & 18,1 & 16,4 & 3,2 & 8,1 & 102,3 & 1 \\
\hline Níquel & 5,6 & 10,6 & $\ldots$ & 3,9 & 195,1 & 3 \\
\hline Banano & 9,0 & 9,2 & 2,9 & 0,3 & 106,0 & 3 \\
\hline Petróleo & 14,7 & 7,7 & 6,6 & $\ldots$ & 166,2 & 2 \\
\hline Gas natural & 1,5 & 1,5 & $\ldots$ & $\ldots$ & 106,3 & 14 \\
\hline Azúcar & 6,1 & 0,8 & 2,1 & 1,0 & 107,8 & 2 \\
\hline
\end{tabular}

Fuente: CEPAL, sobre la base de información de diversas fuentes: FAO (2004); The Economist Intelligence Unit (2005); autoridades chinas; Heren Energy Ltd.; Secretaría de la OPEP; UNCTAD (2003); World Bureau of Metal Statistics (2005); ISSB Monthly World I\&S Review (2005) disponible en www.steelonthenet.com/production.html.), e International Iron and Steel Institute (2005).

Además, la mayoría de las actividades de ensamblaje son realizadas, no por las empresas nacionales chinas, sino por empresas extranjeras, y especialmente empresas de origen taiwanés, que utilizan a China como plataforma de exportación. Todo esto indica que aún falta mucho para que se concrete la transición de China desde ser un país importador neto hasta convertirse en un exportador neto de bienes de alta tecnología.

\section{El papel de las empresas extranjeras en la pro- ducción y el comercio exterior}

Las estrategias de inserción internacional de China e India presentan características muy diferentes. En tanto que China basa su expansión internacional en la atracción de inversión extranjera directa (IED) destinada a producir para la exportación, India hasta hace poco mostraba cautela en la apertura de su economía a esta clase de inversión. Entre los distintos tipos de empresas de capital foráneo que operan en China, el grupo que hace la mayor contribución de IED es el de las empresas de capital exclusivamente extranjero, que aportaron el $62 \%$ de la IED total en China en el 2005, superando por un amplio margen a las empresas de capital mixto. Por su parte, las empresas extranjeras, sea de capital exclusivamente extranjero o de capital mixto, representan solamente el 3\% de las empresas existentes en China, aportan el 28,5\% del valor agregado industrial total del país, el 20,5\% de los ingresos tributarios y el $58 \%$ del total exportado por China. Asimismo, estas empresas originaron el $89 \%$ de las exportaciones de productos de alta tecnología. Pese al gran dinamismo exportador de las empresas extranjeras, su comercio está concentrado en un número relativamente limitado de ellas.

Aunque China ha sido un importante receptor neto de IED durante las dos últimas décadas, últimamente está invirtiendo en el exterior, hasta el punto de ocupar la sexta posición entre los países en desarrollo que generan corrientes de IED. Hasta fines del 2004, las compañías chinas no financieras tenían inversiones por 33.200 millones de dólares en el extranjero, de las cuales 2.850 millones se invirtieron en el 2003. Pese a su participación relativamente reducida, China está emergiendo como uno de los principales inversores entre los países en desarrollo, con un monto semejante al de la República de Corea. La IED china en el exterior alcanzó a 5.500 millones de dólares en el 2004, un 32\% de los cuales ( 1.760 millones) se dirigieron a América Latina y el Caribe. Un caso destacado de IED china 
en la región es el de Lenovo en el estado mexicano de Chihuahua, donde esta empresa estableció cuatro plantas de suministro de partes y equipos (Gobierno de China, 2006). También aumentó la IED de América Latina en China: de acuerdo con el Ministerio de Comercio del país asiático, hasta fines del 2005 las empresas latinoamericanas habían financiado 17.956 proyectos en China por una suma de 56.900 millones de dólares. ${ }^{4}$

La apertura de India a la IED ha sido más lenta. Los ingresos de capital extranjero en el año fiscal 2005/2006 solo llegaron a 5.100 millones de dólares. Sin embargo, este valor es el más alto que se ha registrado y representa un incremento del $60 \%$ con respecto al año anterior. Este nuevo dinamismo de la IED parece obedecer a las políticas formuladas para atraer a inversionistas, entre las cuales se encuentran las de zonas económicas especiales.

\section{Desafíos y perspectivas}

Otra diferencia importante entre China e India es que la apertura comercial india es más reducida que la china (cuadro 1). Mientras China presenta niveles arancelarios menores y lineales, India mantiene todavía bolsones de protección, sobre todo en el sector agrícola. China ha asumido compromisos en todos los sectores de servicios comerciales cubiertos por el Acuerdo General sobre el Comercio de Servicios (GATS); se trata de 93 sectores, que incluyen los subsectores de servicios financieros y telecomunicaciones. En cambio, India lo ha hecho solo en 37 sectores (omc, 2006). De este modo, la reducción de los aranceles y las barreras no arancelarias que se está aplicando en el marco del tratado comercial de la ASEAN con China y en virtud del acuerdo comercial entre China e India — que podría entrar en vigor a partir del 2007 y que comprende productos tanto industriales como agrícolas- puede incidir mucho en el futuro del comercio latinoamericano con esa región asiática, particularmente en términos de desviación de comercio.

Como se señaló más atrás, India ha seguido desarrollándose y todavía tiene un gran potencial de crecimiento dentro del sector de las tecnologías de información y comunicaciones y de las actividades relacionadas con la externalización de procesos empresariales. Sin em-

\footnotetext{
${ }^{4}$ Información disponible en http://www.gov.cn/misc/2006-10/06/ content_405906.htm.
}

bargo, los servicios en el ámbito de las tecnologías de la información y las comunicaciones aún constituyen una pequeña parte del sector de los servicios en su conjunto. Un gran desafío para la expansión de estos servicios es la actual subinversión en capital tecnológico y capital humano, frente a la magnitud de la dinámica expansión de dichas tecnologías. El comercio y la IED aún no se articulan estrechamente, a diferencia de lo que ocurre en China. Este hecho no solo dificulta una mayor inserción del país en los mercados mundiales de productos que incorporen valor agregado y conocimiento, sino que también obstaculiza su ingreso a la dinámica red asiática de comercio intraempresa e intraindustrial.

La aceleración experimentada en el 2006 y durante el primer semestre del 2007 por la ya boyante economía china pone de manifiesto el riesgo de un crecimiento desenfrenado, que nutrido por su enorme superávit comercial genere justificadas presiones para una mayor apreciación del yuan. De hecho, no se asegura una moderación del crecimiento. Además, como lo plantea el décimo primer Plan Quinquenal para el Desarrollo Nacional Económico y Social (2006-2010), urge abordar las debilidades estructurales del país derivadas de su rápida industrialización y modernización; entre ellas se hallan la capacidad ociosa en algunos sectores, una mayor desigualdad del ingreso, sobre todo entre las áreas urbanas y rurales y entre el litoral y el interior del país, así como los agudos problemas ambientales. El objetivo principal del Plan es promover un enfoque de crecimiento más equilibrado, equitativo y sostenible, con estrategias dirigidas especialmente a la corrección de los problemas señalados. Este Plan podría cambiar la composición de la demanda agregada y moderar el crecimiento económico para hacerlo más sostenible en el largo plazo.

Las perspectivas de corto plazo de India son promisorias: seguirá creciendo entre un $7 \%$ y un $9 \%$ en los próximos años, con una inflación moderada. Sin embargo, a mediano plazo deberá encarar altos niveles de endeudamiento público, un creciente déficit en cuenta corriente y la necesidad de abordar las reformas. Urge que el gobierno continúe consolidando su posición fiscal, asegurando en tanto mejoras de infraestructura (especialmente en el suministro eléctrico y el sistema vial) que apoyen el desarrollo industrial, así como la capacitación de recursos humanos en sectores relacionados con los servicios y la inversión pública necesaria para avanzar en materia de productividad rural. 


\section{III}

\section{Crecientes relaciones comerciales de América Latina y el Caribe con China e India}

Entre 1990 y el 2005 los intercambios comerciales entre los países de la región y China e India aumentaron de manera considerable, sobre todo en el último quinquenio. Llama la atención la semejanza de los patrones de intercambio de uno y otro país con los de las subregiones de América Latina. Mientras América del Sur presenta superávit comerciales con ambos, México y Centroamérica mantienen déficit cada vez mayores (cuadro 3). Por otro lado, la estructura de las exportaciones de América Latina y el Caribe hacia China e India se caracteriza por la concentración en recursos naturales y manufacturas basadas en recursos naturales, en fuerte contraste con la estructura del comercio intrarregional latinoamericano, que tiene un alto componente de productos de mediano nivel tecnológico. Para su rápido crecimiento, China necesita asegurar el abastecimiento de materias primas, alimentos y productos energéticos. Al mismo tiempo, busca un mercado favorable para sus exportaciones y desea aminorar las acusaciones de uso de medidas de defensa comercial, como las de antidumping, que son consideradas "abusivas"; con este propósito se ha esforzado por conseguir el estatus de economía de mercado otorgado por 27 países, entre los cuales se encuentran siete de América Latina y el Caribe (CEPAL, 2005).

América Latina y el Caribe: exportaciones hacia China e India, 2005

(En millones de dólares y porcentajes del total)

\begin{tabular}{|c|c|c|c|c|c|c|c|}
\hline \multirow{2}{*}{ Países } & \multicolumn{3}{|c|}{ Exportaciones totales según destino } & \multicolumn{2}{|c|}{$\begin{array}{c}\text { Porcentaje del total de } \\
\text { América Latina y el } \\
\text { Caribe }\end{array}$} & \multicolumn{2}{|c|}{$\begin{array}{l}\text { Porcentaje del total } \\
\text { de cada país }\end{array}$} \\
\hline & India & China & Mundo & India & China & India & China \\
\hline América Latina y el Caribe & 3048 & 19442 & 555445 & 100,0 & 100,0 & 0,5 & 3,5 \\
\hline Comunidad Andina & 115 & 3009 & 106981 & 3,8 & 15,5 & $\mathbf{0 , 1}$ & 2,8 \\
\hline Bolivia & 1 & 19 & 2734 & 0,0 & 0,1 & 0,0 & 0,7 \\
\hline Colombia & 5 & 237 & 21187 & 0,2 & 1,2 & 0,0 & 1,1 \\
\hline Ecuador & 26 & 82 & 10649 & 0,8 & 0,4 & 0,2 & 0,8 \\
\hline Perú & 79 & 1826 & 17001 & 2,6 & 9,4 & 0,5 & 10,7 \\
\hline Venezuela (Rep. Bolivariana de) & 4 & 845 & 55410 & 0,1 & 4,3 & 0,0 & 1,5 \\
\hline Mercosur & 1875 & 10317 & 163414 & 61,5 & 53,1 & 1,1 & 6,3 \\
\hline Argentina & 729 & 3302 & 40013 & 23,9 & 17,0 & 1,8 & 8,3 \\
\hline Brasil & 1137 & 6834 & 118308 & 37,3 & 35,2 & 1,0 & 5,8 \\
\hline Paraguay & 5 & 61 & 1688 & 0,2 & 0,3 & 0,3 & 3,6 \\
\hline Uruguay & 4 & 120 & 3405 & 0,1 & 0,6 & 0,1 & 3,5 \\
\hline Chile & 493 & 4390 & 39536 & 16,2 & 22,6 & 1,2 & 11,1 \\
\hline Mercado Común Centroamericano & 17 & 349 & 21806 & 0,6 & 1,8 & $\mathbf{0 , 1}$ & 1,6 \\
\hline Costa Rica & 8 & 245 & 7090 & 0,3 & 1,3 & 0,1 & 3,5 \\
\hline El Salvador & 2 & 2 & 3383 & 0,1 & 0,0 & 0,0 & 0,1 \\
\hline Guatemala & 3 & 80 & 5381 & 0,1 & 0,4 & 0,1 & 1,5 \\
\hline Honduras & 5 & 15 & 4377 & 0,2 & 0,1 & 0,1 & 0,3 \\
\hline Nicaragua & 0 & 7 & 1574 & 0,0 & 0,0 & 0,0 & 0,4 \\
\hline México & 522 & 1091 & 213711 & 17,1 & 5,6 & 0,2 & 0,5 \\
\hline Otros países de América Latina y el Caribe & 26 & 287 & 9998 & 0,9 & 1,5 & $\mathbf{0 , 3}$ & 2,9 \\
\hline Panamá & 22 & 23 & 2013 & 0,7 & 0,1 & 1,1 & 1,1 \\
\hline Cuba & 2 & 247 & 2430 & 0,1 & 1,3 & 0,1 & 10,2 \\
\hline Rep. Dominicana & 3 & 17 & 5554 & 0,1 & 0,1 & 0,0 & 0,3 \\
\hline
\end{tabular}

Fuente: CEPAL sobre la base de información oficial de los países y datos extraídos de FMI (2006a y b). 


\section{Relaciones comerciales con China tanto de América del Sur como de Centroamérica y México}

Si bien el crecimiento de China y su demanda creciente de productos primarios influyen positivamente sobre los términos de intercambio, el impacto ha sido desigual entre las distintas subregiones. Por un lado, América del Sur, especialmente los países exportadores de petróleo y metales, se beneficia por la mayor demanda china de productos básicos y por los menores precios de las manufacturas que compra a China. Los buenos precios de estos productos han propiciado en estos países términos de intercambio que estimulan el ahorro y las cuentas fiscales. Por otro lado, el auge de la demanda china de productos primarios no ha favorecido a los países de América Central que son importadores netos de petróleo y exportadores de productos textiles y de confecciones; más bien la competencia con China en el mercado estadounidense de manufacturas ha tendido a deteriorar sus términos de intercambio.

China es ya uno de los principales mercados receptores de las exportaciones de varios países de la región (gráfico 1). Su comercio con los países de América del Sur ha sido muy favorable para estos últimos, de modo que hasta el 2005 la subregión había acumulado un superávit que había crecido por cuatro años consecutivos (gráfico 2). Sin embargo, el superávit acumulado se concentra en productos primarios y manufacturas basadas en recursos naturales, con un marcado aumento del déficit en manufacturas que incorporan tecnología. América del Sur suministra, por ejemplo, más del $60 \%$ de las importaciones chinas de soja, principalmente desde Brasil y Argentina; $80 \%$ de harina de pescado, desde Perú y Chile; cerca de $60 \%$ de despojos de aves troceados, desde Argentina y Brasil; y $45 \%$ de vinos y uvas, de Chile (cuadro 4). Por otro lado, la canasta exportadora de los países de esa subregión se concentra en un número bastante reducido de productos. En el caso de Argentina, por ejemplo, tres productos (semillas de soja, aceite de soja y petróleo) constituyen más del $84 \%$ de sus exportaciones totales hacia China. Un caso similar es el de Chile, donde tres productos (cobre refinado, concentrado de cobre y pulpa de madera) constituyen el $85 \%$ de sus exportaciones totales al país asiático.

GRÁFICO 1

China: participación en las exportaciones totales de América Latina y el Caribe, 1990 y 2005

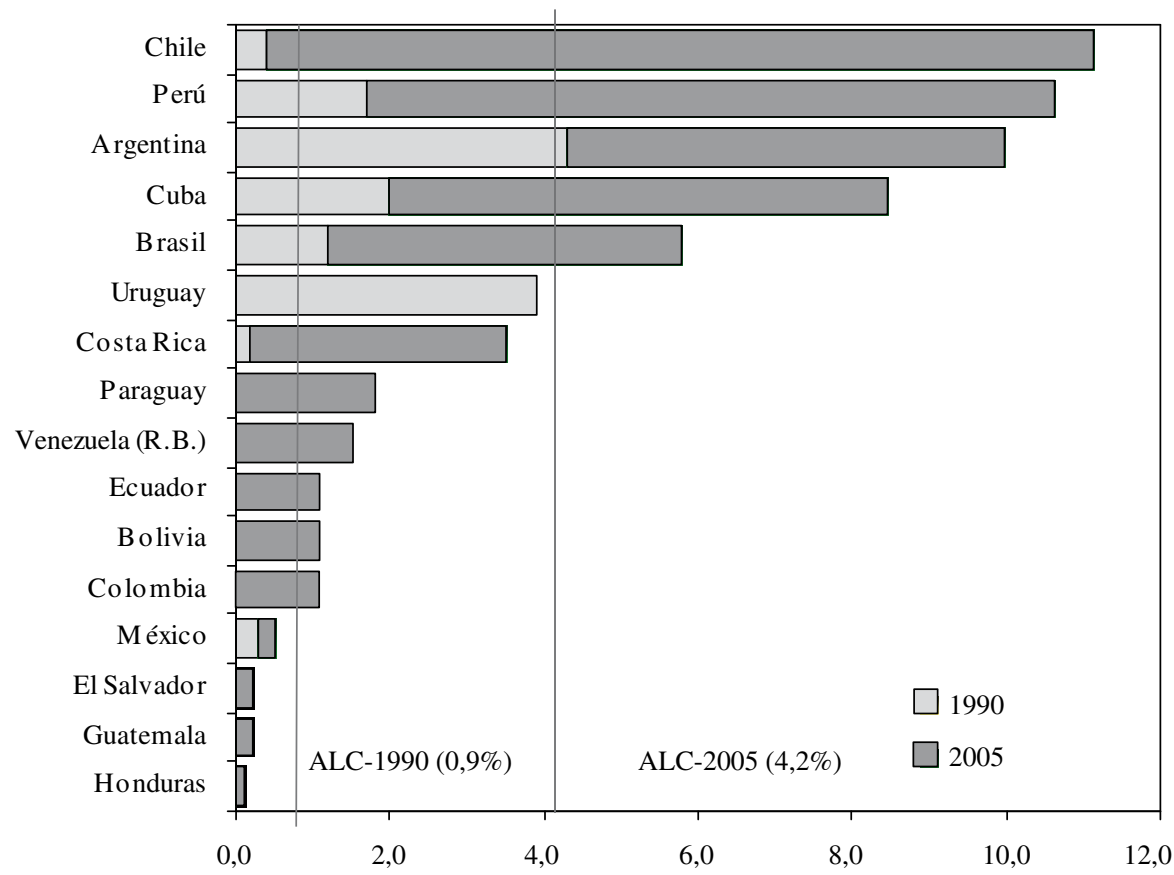

Fuente: CEPAL, con información obtenida de la Base de datos estadísticos sobre el comercio de mercaderías (COMTRADE). 
GRÁFICO 2

China: balance comercial con América del Sur, 1990 y 2005

(Millones de dólares)

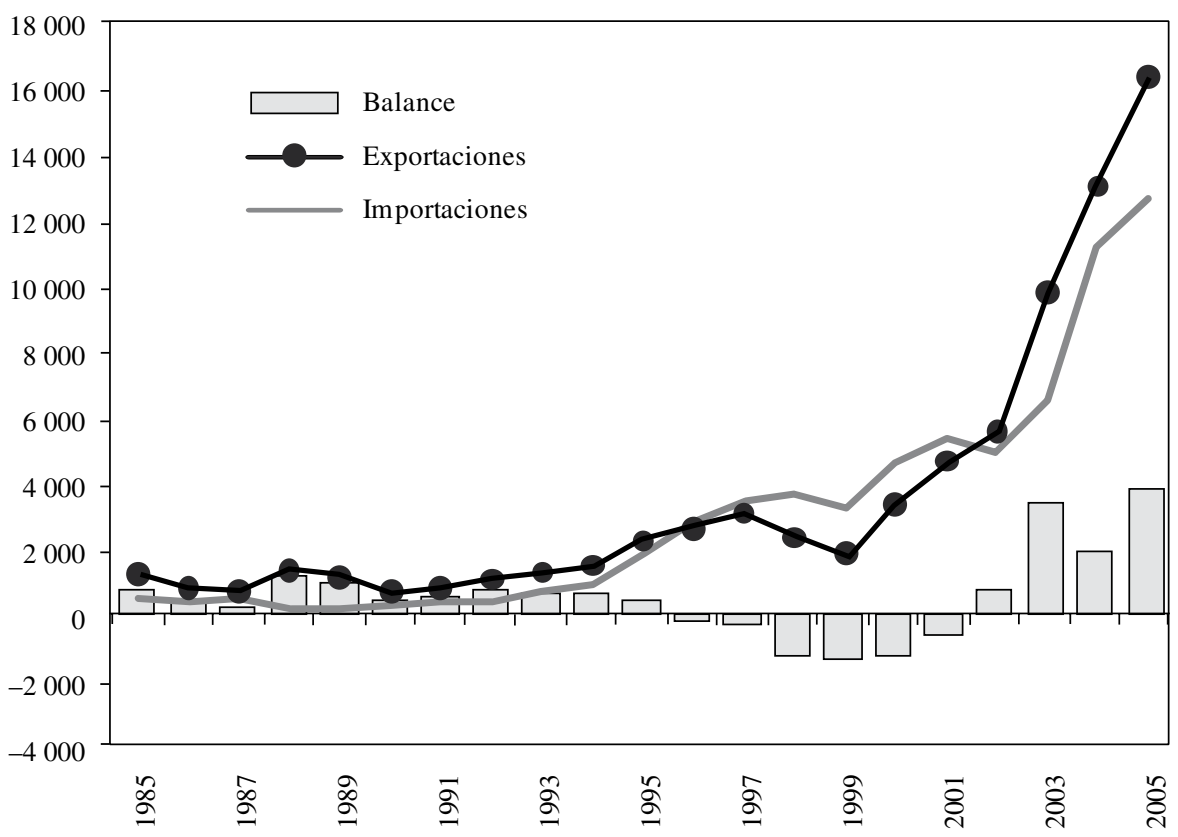

Fuente: CEPAL, con información obtenida de la Base de datos estadísticos sobre el comercio de mercaderías (COMTRADE).

CUADRO 4

China: 15 principales productos importados desde América del Sur, 2004

(En millones de dólares y porcentajes del total) ${ }^{\mathrm{a}}$

\begin{tabular}{|c|c|c|c|c|c|c|c|c|}
\hline $\begin{array}{l}\text { Principales productos } \\
\mathrm{C}=(\mathrm{A}) /(\mathrm{B})\end{array}$ & Argentina & Brasil & Chile & Perú & $\begin{array}{l}\text { Resto de } \\
\text { América } \\
\text { del Sur }\end{array}$ & $\begin{array}{l}\text { América } \\
\text { del Sur } \\
\text { (A) }\end{array}$ & $\begin{array}{l}\text { Mundo } \\
\text { (B) }\end{array}$ & $\begin{array}{l}\text { Porcentaje } \\
\text { total } \\
\text { (C) }\end{array}$ \\
\hline Soja $(2222+4232)$ & 2555 & 2619 & 0 & 0 & 0 & 5174 & 8528 & 60,7 \\
\hline Hierro $(2815+2816+6712+6725+6746)$ & 25 & 3252 & 168 & 256 & 208 & 3909 & 19677 & 19,9 \\
\hline Cobre $(2871+2882+6821+6822)$ & 12 & 40 & 2793 & 540 & 73 & 3456 & 13532 & 25,5 \\
\hline Madera y pulpa $(2482+2483+2517+6416)$ & 36 & 527 & 371 & 4 & 6 & 943 & 4584 & 2,6 \\
\hline Petróleo crudo (3330) & 183 & 423 & 0 & 0 & 139 & 745 & 33912 & 2,2 \\
\hline Harina de pescado (0814) & 17 & 0 & 103 & 502 & 2 & 623 & 770 & 80,9 \\
\hline Cueros y lanas $(6114+6512+6129+2681)$ & 145 & 301 & 2 & 1 & 88 & 537 & 4152 & 12,9 \\
\hline Ferroaleaciones $(6713+6716+6727+6749)$ & 6 & 203 & 0 & 0 & 233 & 442 & 9613 & 4,6 \\
\hline Plomo (2874) & 0 & 0 & 0 & 122 & 0 & 122 & 437 & 27,9 \\
\hline Aluminio $(2873+6845)$ & 0 & 67 & 0 & 0 & 37 & 105 & 2069 & 5,1 \\
\hline Otras partes y accesorios para vehículos (7849) & 3 & 101 & 0 & 0 & 0 & 104 & 7305 & 1,4 \\
\hline Aves y despojos de aves troceados (0114) & 37 & 53 & 0 & 0 & 0 & 90 & 154 & 58,7 \\
\hline Algodón $(2631+2632+2633+2634)$ & 0 & 31 & 0 & 0 & 49 & 80 & 3242 & 2,5 \\
\hline Tabaco (1211-1212) & 0 & 74 & 0 & 0 & 0 & 74 & 232 & 31,6 \\
\hline Uvas y vinos $(0575+1121)$ & 1 & 0 & 61 & 0 & 0 & 61 & 135 & 45,4 \\
\hline Total muestra & 3019 & 7690 & 3497 & 1424 & 834 & 16465 & 108342 & 15,2 \\
\hline Otros productos & 236 & 978 & 170 & 99 & 148 & 1630 & 442973 & 0,4 \\
\hline Total importaciones & 3255 & 8669 & 3667 & 1523 & 982 & 18095 & 551315 & 3,3 \\
\hline
\end{tabular}

Fuente: CEPAL, con información obtenida de la Base de datos estadísticos sobre el comercio de mercaderías (COMTRADE).

a Clasificación Uniforme del Comercio Internacional (CUCI, Rev. 2). 
La composición de los productos que México y Centroamérica exportan al mercado estadounidense se asemeja a la de los productos que China vende a dicho mercado (gráfico 3, sección A). Tanto esa subregión como China exportan manufacturas de nivel tecnológico mediano y alto (por ejemplo, artículos eléctricos y electrónicos, incluidos equipos de computación y productos de la industria automotriz) y de nivel tecnológico bajo (como textiles y prendas de vestir). Desde esta perspectiva, la tendencia proteccionista de los Estados Unidos afecta a ambas regiones de manera interrelacionada, como lo ilustra la negociación del Tratado de Libre Comercio entre la República Dominicana, Centroamérica y los Estados Unidos en el 2004 (CEPAL, 2005).
En efecto, un análisis detallado de la estructura de las importaciones de los Estados Unidos desde América Latina y el Caribe muestra que entre las 30 principales categorías de productos - a nivel de tres dígitos de la Clasificación Uniforme para el Comercio Internacional (CUCI, Rev. 2)- que importó Estados Unidos desde América Latina y el Caribe en 2004, México compitió cara a cara con China en calidad de principales proveedores en 20 categorías (cuadro 5). Las áreas en que compiten estos dos países en los mercados estadounidenses van desde los sectores eléctrico/electrónico, de maquinaria, de vehículos automotores y de muebles hasta los de textiles y de confección.

GRÁFICO 3

México y Centroamérica: relación con China y sus repercusiones en el mercado estadounidense, 2005

A. Estructura de las exportaciones a los Estados Unidos

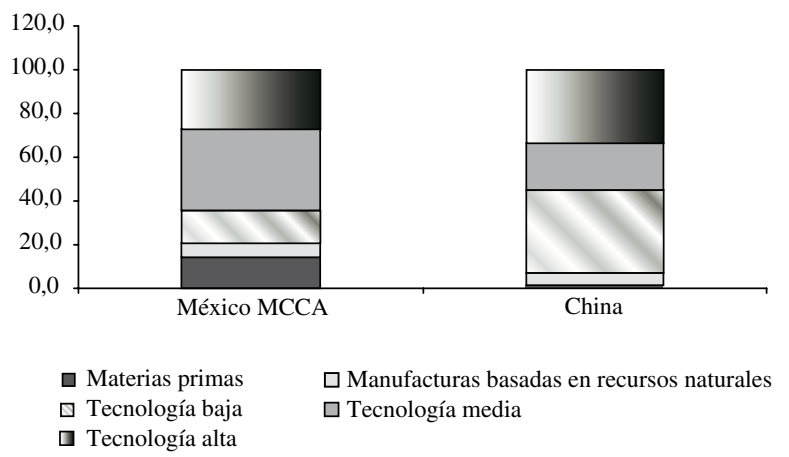

C. Participación porcentual en las importaciones de confecciones

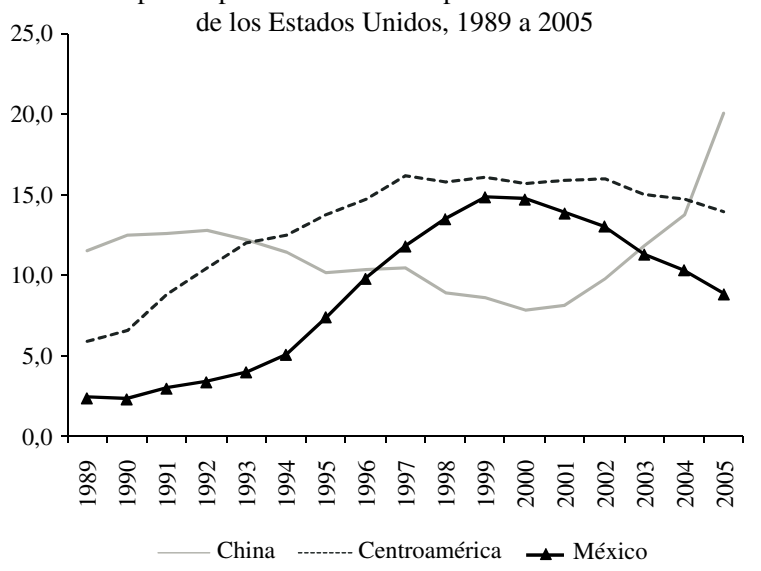

B. Importaciones de los Estados Unidos desde China y México (En millones de dólares)

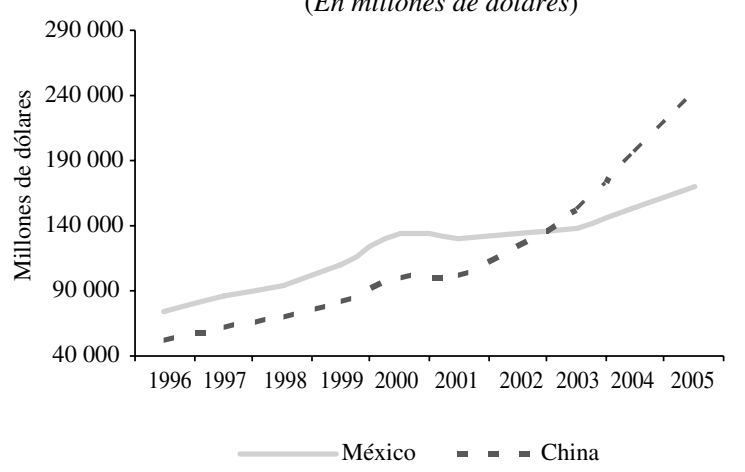

D. México y Centroamérica: comercio con China

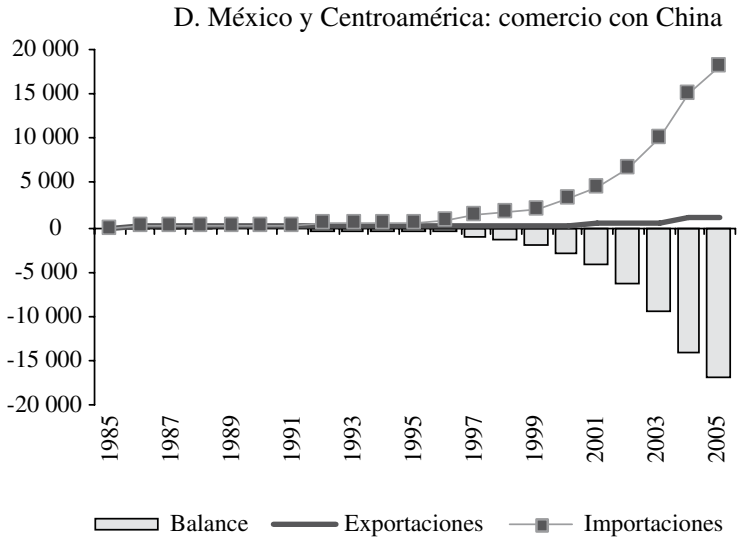

Fuente: CEPAL, con información obtenida de la Base de datos estadísticos sobre el comercio de mercaderías (COMTRADE). 
CUADRO 5

Estados Unidos: 30 principales productos importados desde

América Latina y el Caribe y sus competidores, 2004

(En millones de dólares y porcentajes)

\begin{tabular}{|c|c|c|c|c|c|c|c|c|c|c|}
\hline & Código & Descripción de los productos & Valor & $\begin{array}{c}\text { Mundo } \\
\%\end{array}$ & & & & & & Total \\
\hline & $\begin{array}{l}\text { CUCI, } \\
\text { Rev. } 2\end{array}$ & 1 & 2 & 3 & & & 4 & & & 5 \\
\hline 1 & 333 & Petróleo crudo & 23746 & 16,6 & SAU & CAN & VEN & MEX & NGA & 65,9 \\
\hline 2 & 781 & Automóviles para pasajeros, excepto buses & 10449 & 8,4 & CAN & JPN & DEU & MEX & KOR & 89,6 \\
\hline 3 & 752 & Maquinarias para elaboración automática de datos & 10291 & 16,9 & $\mathrm{CHN}$ & MYS & MEX & SGP & TWN & 78,7 \\
\hline 4 & 764 & Equipos de telecomunicaciones y partes n.e. & 9668 & 18,8 & $\mathrm{CHN}$ & KOR & MEX & MYS & $\mathrm{CAN}$ & 73,4 \\
\hline 5 & 784 & Partes y accesorios de los vehículos automotores & 8930 & 22,8 & CAN & JPN & MEX & $\mathrm{DEU}$ & $\mathrm{CHN}$ & 82,0 \\
\hline 6 & 761 & Receptores de televisión & 7534 & 46,0 & MEX & $\mathrm{CHN}$ & JPN & TWN & KOR & 87,3 \\
\hline 7 & 782 & $\begin{array}{l}\text { Vehículos automotores para el transporte de } \\
\text { mercancías }\end{array}$ & 6578 & 37,3 & CAN & $\mathrm{CHN}$ & JPN & GBR & SWE & 98,4 \\
\hline 8 & 778 & Máquinas y aparatos eléctricos n.e. & 6520 & 34,1 & $\mathrm{CHN}$ & MEX & JPN & CAN & TWN & 72,7 \\
\hline 9 & 773 & Material de distribución de electricidad & 6363 & 65,3 & MEX & $\mathrm{CHN}$ & CAN & PHL & JPN & 84,1 \\
\hline 10 & 772 & $\begin{array}{l}\text { Aparatos eléctricos para empalme, corte, } \\
\text { protección }\end{array}$ & 5435 & 36,1 & MEX & JPN & $\mathrm{CHN}$ & $\mathrm{DEU}$ & $\mathrm{CAN}$ & 70,8 \\
\hline 11 & 821 & Muebles y sus partes & 4693 & 15,1 & $\mathrm{CHN}$ & CAN & MEX & ITA & TWN & 79,3 \\
\hline 12 & 713 & $\begin{array}{l}\text { Motores de combustión interna, de émbolo y sus } \\
\text { partes }\end{array}$ & 4671 & 24,9 & JPN & CAN & MEX & DEU & BRA & 87,4 \\
\hline 13 & 334 & Productos derivados del petróleo & 4567 & 11,3 & $\mathrm{CAN}$ & VEN & RUS & GBR & NLD & 43,2 \\
\hline 14 & 054 & $\begin{array}{l}\text { Legumbres frescas, refrigeradas, congeladas o } \\
\text { conserv. }\end{array}$ & 3205 & 64,5 & MEX & CAN & PER & NLD & $\mathrm{CHN}$ & 88,5 \\
\hline 15 & 057 & Frutas y nueces excepto las nueces oleaginosas & 3130 & 54,3 & $\mathrm{CHL}$ & MEX & CRI & GTM & $\mathrm{ECU}$ & 62,6 \\
\hline 16 & 699 & Manufacturas de metales comunes, n.e. & 2819 & 23,7 & $\mathrm{CHN}$ & MEX & CAN & TWN & JPN & 75,3 \\
\hline 17 & 759 & $\begin{array}{l}\text { Partes y accesorios destinados a máquinas de } \\
\text { correspondientes a dígitos } 751 \text { o } 752\end{array}$ & 2800 & 9,2 & $\mathrm{CHN}$ & JPN & MYS & TWN & SGP & 74,9 \\
\hline 18 & 872 & Instrumentos y aparatos de medicina, n.e. & 2647 & 27,6 & IRL & MEX & $\mathrm{DEU}$ & $\mathrm{CHN}$ & JPN & 65,5 \\
\hline 19 & 792 & Aeronaves y equipo conexo y sus partes n.e. & 2643 & 16,0 & CAN & FRA & BRA & DEU & JPN & 82,6 \\
\hline 20 & 842 & Ropa exterior para hombres y niños, de tejidos & 2544 & 23,3 & MEX & CHN & DOM & VNM & BGD & 47,6 \\
\hline 21 & 716 & $\begin{array}{l}\text { Aparatos eléctricos rotativos y sus partes y piezas } \\
\text { sueltas }\end{array}$ & 2535 & 39,0 & MEX & JPN & $\mathrm{CHN}$ & CAN & DEU & 72,7 \\
\hline 22 & 776 & Lámparas, tubos y válvulas eléctricas de cátodo & 2423 & 8,7 & KOR & TWN & MYS & JPN & PHL & 62,0 \\
\hline 23 & 874 & $\begin{array}{l}\text { Instrumentos y aparatos de medición, } \\
\text { comprobación }\end{array}$ & 2309 & 14,5 & JPN & MEX & DEU & GBR & $\mathrm{CHN}$ & 64,0 \\
\hline 24 & 749 & Partes y accesorios no eléctricos de máquinas, n.e. & 2240 & 15,0 & JPN & CAN & DEU & MEX & $\mathrm{CHN}$ & 66,3 \\
\hline 25 & 893 & $\begin{array}{l}\text { Artículos n.e. de los materiales descritos en el } \\
\text { capítulo } 58\end{array}$ & 2212 & 16,7 & $\mathrm{CHN}$ & CAN & MEX & TWN & JPN & 77,8 \\
\hline 26 & 971 & Oro no monetario que no tenga curso legal & 2193 & 54,8 & CAN & PER & $\mathrm{COL}$ & BRA & MEX & 87,6 \\
\hline 27 & 846 & Ropa interior de punto o ganchillo & 2017 & 18,7 & HND & MEX & SLV & $\mathrm{CHN}$ & DOM & 44,5 \\
\hline 28 & 843 & Ropa exterior para mujeres y niñas, n.e. & 2011 & 10,5 & $\mathrm{CHN}$ & MEX & $\mathrm{HKG}$ & IDN & IND & 49,1 \\
\hline 29 & 775 & $\begin{array}{l}\text { Aparatos de uso doméstico, eléctricos y no } \\
\text { eléctricos }\end{array}$ & 1953 & 16,7 & $\mathrm{CHN}$ & MEX & KOR & CAN & DEU & 83,4 \\
\hline 30 & 682 & Cobre & 1914 & 39,5 & $\mathrm{CAN}$ & CHL & PER & MEX & $\mathrm{DEU}$ & 72,5 \\
\hline \multicolumn{3}{|c|}{ Otros productos } & 65913 & & & & & & & \\
\hline \multicolumn{3}{|c|}{ Comercio total } & 216953 & & & & & & & \\
\hline
\end{tabular}

Fuente: base de datos estadísticos sobre el comercio de mercaderías (COMTRade) de la División de Estadística de las Naciones Unidas.

a La columna 1 presenta los 30 principales productos importados por Estados Unidos desde América Latina y el Caribe, basándose en el valor de las importaciones en 2004. La columna 2 detalla el valor de las importaciones de estos productos en 2004. La columna 3 corresponde a la participación del producto importado desde América Latina y el Caribe en las importaciones totales del producto desde el mundo. La columna 4 indica los cinco principales proveedores del producto. La columna 5 presenta la participación de estos cinco países en el valor total de las importaciones. 
A diferencia de América del Sur, México registra un déficit enorme y cada vez mayor en su comercio con China. El intercambio comercial entre ambos se concentra en productos de tecnología mediana y alta, si bien México es deficitario en todas las agrupaciones de productos consideradas, trátese de productos primarios o de manufacturas. Además, México ha sido desplazado por China como segundo socio principal de los Estados Unidos, después de Canadá (gráfico 3, sección B). Esto se observa claramente en los textiles y confecciones, sectores en los que tanto México como Centroamérica han perdido una parte importante del mercado (gráfico 3, sección C). Algo similar, pero aún más acentuado, sucede en el sector de artículos eléctricos y electrónicos, especialmente en lo que se refiere a equipos de computación (Dussel Peters, 2005).

Por otra parte, el comercio entre China y México es muy asimétrico; la participación de China en las exportaciones totales de México no alcanza siquiera al $1 \%$, mientras que el país asiático ocupa la segunda posición entre los países de origen de las importaciones mexicanas. En consecuencia, México y Centroamérica acumulan un déficit comercial creciente con China (gráfico 3, sección D). Tal asimetría se refleja además en el hecho de que los 15 productos que predominan en las importaciones de China desde México y Centroamérica son manufacturas, sobre todo del sector electrónico, con la excepción del cobre y el mineral de hierro. La participación de cada producto en el mercado chino es todavía muy reducida (cuadro 6).

En vista de esta tendencia, la subregión debería fortalecer los vínculos comerciales y buscar una mayor Complementariedad productiva con China en lugar de competir solamente en los mercados principales (los Estados Unidos y la Unión Europea), estableciendo para ello las alianzas comerciales y tecnológicas necesarias. De esta forma no solo se beneficiaría con la adquisición de estándares internacionales de calidad sino que además podría buscar modalidades de complementación comercial que ayudaran a evitar posibles presiones proteccionistas de estos países industrializados.

CUADRO 6

China: 15 principales productos importados desde México y Centroamérica, 2004 (En millones de dólares y porcentajes)

\begin{tabular}{|c|c|c|c|c|c|c|c|c|}
\hline Principales productos (CUCI, Rev.2) & México & $\begin{array}{c}\text { Costa } \\
\text { Rica }\end{array}$ & $\begin{array}{l}\text { Otros países } \\
\text { de Centro- } \\
\text { américa }\end{array}$ & $\begin{array}{c}\text { México y } \\
\text { Centro- } \\
\text { américa } \\
\text { (A.1) }\end{array}$ & $\begin{array}{l}\text { Mundo } \\
\text { (B) }\end{array}$ & $\begin{array}{c}\text { Porcentaje en } \\
\text { el total } \\
\mathrm{C}=(\mathrm{A} .1) /(\mathrm{B})\end{array}$ & $\begin{array}{c}\text { América } \\
\text { del Sur } \\
\text { (A.2) }\end{array}$ & $\begin{array}{c}\text { Porcentaje } \\
\text { en el total } \\
\mathrm{C}=(\mathrm{A} .2) /(\mathrm{B})\end{array}$ \\
\hline Partes y accesorios electrónicos (7599) & 322 & 0 & 0 & 323 & 13887 & 2,3 & 0 & 0,0 \\
\hline Microcircuitos electrónicos (7764) & 263 & 592 & 0 & 856 & 61047 & 1,4 & 2 & 0,0 \\
\hline Cobre y sus concentrados (2871) & 133 & 0 & 0 & 133 & 2236 & 5,9 & 1217 & 54,4 \\
\hline Lingotes de hierro (6725) & 125 & 0 & 0 & 125 & 1443 & 8,7 & 186 & 12,9 \\
\hline Desperdicios y desechos de metales (2882) & 116 & 1 & 20 & 138 & 3577 & 3,8 & 144 & 4,0 \\
\hline Otras maquinarias eléctricas y equipos (7788) & 110 & 1 & 1 & 111 & 7503 & 1,5 & 14 & 0,2 \\
\hline Diodos, transistores y fotocélulas (7763) & 74 & 8 & 0 & 82 & 7416 & 1,1 & 0 & 0,0 \\
\hline Aparatos eléctricos para empalme, etc. (7721) & 65 & 2 & 0 & 67 & 8673 & 0,8 & 8 & 0,1 \\
\hline Compuestos heterocíclicos con oxígeno (5156) & 58 & 0 & 0 & 58 & 1247 & 4,6 & 8 & 0,7 \\
\hline Ácidos policarboxílicos (5138) & 55 & 0 & 0 & 55 & 5106 & 1,1 & 4 & 0,1 \\
\hline Partes y piezas de motores de combustión interna (7139) & 53 & 0 & 0 & 53 & 1671 & 3,2 & 33 & 2,0 \\
\hline Estopas de filamentos sintéticos (2666) & 51 & 0 & 0 & 51 & 383 & 13,2 & 2 & 0,5 \\
\hline Partes y accesorios para vehículos (7849) & 48 & 0 & 0 & 48 & 7305 & 0,7 & 104 & 1,4 \\
\hline Aglomerados de mineral de hierro (2816) & 41 & 0 & 0 & 41 & 1824 & 2,2 & 741 & 40,6 \\
\hline Partes y piezas de grabadores de sonido (7649) & 39 & 2 & 0 & 41 & 17868 & 0,2 & 5 & 0,0 \\
\hline Total muestra & 1553 & 606 & 21 & 2180 & 141187 & 1,5 & 2470 & 1,7 \\
\hline Otros productos & 587 & 35 & 55 & 704 & 410128 & 0,2 & 15625 & 3,8 \\
\hline Total importaciones & 2140 & 641 & 76 & 2900 & 551315 & 0,5 & 18095 & 3,3 \\
\hline
\end{tabular}

Fuente: CEPAL, con información de la Base de datos estadísticos sobre el comercio de mercaderías (COMTRADE). 


\section{El comercio de América Latina y el Caribe con India}

El mercado latinoamericano y caribeño aún no resulta muy significativo para India, aunque su importancia es cada vez mayor. En el año fiscal abril 2005/marzo 2006, la región representó menos del 3,0\% (2.993 millones de dólares) de las exportaciones de India y un 1,8\% (2.663 millones de dólares) de las importaciones de ese país, lo que arrojó un superávit a favor de la nación asiática (cuadro 7).

Como en el caso del intercambio de la región con China, la canasta que India importa desde América Latina y el Caribe está poco diversificada: los 15 prin- cipales productos, según el Sistema Armonizado de Designación y Codificación de Mercancías a cuatro dígitos, representaron cerca de $77 \%$ del total en el año fiscal 2005/2006 (cuadro 7). La mayoría de ellos son productos primarios o manufacturas basadas en recursos naturales. La soja, el cobre y sus concentrados, otros metales, las maderas y los alcoholes son los principales productos latinoamericanos que se exportan a India. $\mathrm{La}$ canasta exportadora del país asiático hacia la región es también concentrada: los 15 productos principales abarcan cerca de $60 \%$ del total exportado. El petróleo, los medicamentos, los automóviles, los productos químicos y los productos textiles y de confección son los sectores que más pesan en esta canasta (cuadro 8).

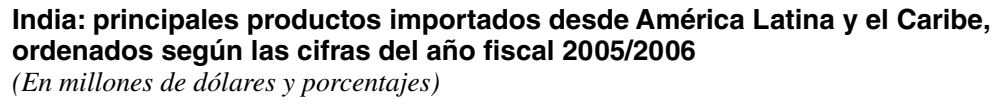

\begin{tabular}{|c|c|c|c|c|c|}
\hline $\mathrm{N}^{\mathrm{o}}$ & $\begin{array}{c}\text { Código } \\
\mathrm{SA}^{\mathrm{a}}\end{array}$ & Productos & 2004-2005 & 2005-2006 & $\begin{array}{c}\% \\
\text { Crecimiento }\end{array}$ \\
\hline 1 & 1507 & Soja & 604,69 & 810,55 & 34,0 \\
\hline 2 & 2603 & Cobre y concentrados & 342,13 & 413,16 & 20,8 \\
\hline 3 & 8901 & Barcos de crucero & 57,95 & 162,26 & 180,0 \\
\hline 4 & 2207 & Alcoholes & 111,69 & 134,31 & 20,3 \\
\hline 5 & 8905 & Barcos ligeros y similares & 76,02 & 130,40 & 71,5 \\
\hline 6 & 1701 & Azúcar de betarraga, de mesa (table sugar) & 193,11 & 118,81 & $-38,5$ \\
\hline 7 & 1512 & Aceite de girasol, azafrán, etc. & 24,43 & 41,65 & 70,5 \\
\hline 8 & 4403 & Maderas en bruto, etc. & 50,37 & 40,65 & $-19,3$ \\
\hline 9 & 7204 & Desperdicios de fierro, etc. & 23,83 & 32,24 & 35,3 \\
\hline 10 & 8473 & Partes y accesorios usados en dígitos 8469 a 8472 & 26,49 & 30,82 & 16,3 \\
\hline 11 & 2613 & Metal de molibdeno y concentrados & 24,27 & 29,38 & 21,0 \\
\hline 12 & 8413 & Bombas para líquidos, elevadores para líquidos & 8,29 & 29,20 & 252,1 \\
\hline 13 & 2601 & Metal de hierro y concentrados & 28,52 & 27,83 & $-2,4$ \\
\hline 14 & 2801 & Fluorino, clorino, bromino y yodo & 13,68 & 27,13 & 98,3 \\
\hline 15 & 4108 & Cueros y pieles de bovino curtidos & 25,44 & 26,00 & 2,2 \\
\hline \multicolumn{3}{|c|}{15 principales productos, subtotal (A) } & 1610,91 & 2054,39 & 27,5 \\
\hline \multicolumn{3}{|c|}{ Total importado desde América Latina y el Caribe (B) } & 2054,80 & 2662,75 & 29,6 \\
\hline \multicolumn{3}{|c|}{ Participación de los 15 principales productos en el total de ALC:(A)/(B)*100 (\%) } & $\mathbf{7 8 , 4}$ & 77,2 & \\
\hline \multicolumn{3}{|c|}{ Total importado desde el mundo (C) } & 111517,44 & 149162,73 & 33,8 \\
\hline \multicolumn{3}{|c|}{ Participación de América Latina en el mundo: $(\mathrm{A}) /(\mathrm{C}) * 100(\%)$} & 1,8 & 1,8 & \\
\hline
\end{tabular}

Fuente: Government of India, Ministry of Commerce \& Industry, Department of Commerce, http://dgft.delhi.nic.in/.

a SA: Sistema Armonizado de Designación y Codificación de Mercancías. 
India: principales productos exportados hacia América Latina y el Caribe, ordenados según las cifras del año fiscal 2005/2006

(En millones de dólares y porcentajes)

\begin{tabular}{|c|c|c|c|c|c|}
\hline $\mathrm{N}^{\mathrm{o}}$ & $\begin{array}{c}\text { Código } \\
\mathrm{SA}^{\mathrm{a}}\end{array}$ & Productos & $2004 / 2005$ & $2005 / 2006$ & $\begin{array}{c}\% \text { de } \\
\text { crecimiento }\end{array}$ \\
\hline 1 & 2710 & Petróleo & 517,49 & 815,81 & 57,7 \\
\hline 2 & 3004 & Medicamentos & 110,25 & 177,85 & 61,3 \\
\hline 3 & 8703 & Automóviles & 104,47 & 132,77 & 27,1 \\
\hline 4 & 2942 & Otros compuestos orgánicos & 105,03 & 132,74 & 26,4 \\
\hline 5 & 3808 & Insecticidas, etc. & 68,62 & 82,51 & 20,2 \\
\hline 6 & 8711 & Motocicletas & 56,93 & 72,52 & 27,4 \\
\hline 7 & 3907 & Poliacetilenos y otros acetilenos, etc. & 23,72 & 58,09 & 144,9 \\
\hline 8 & 8708 & Partes y piezas de automóviles usadas & 36,01 & 57,00 & 58,3 \\
\hline 9 & 4011 & Neumáticos nuevos de goma & 44,04 & 47,14 & 7,0 \\
\hline 10 & 5402 & Hilos y filamentos sintéticos & 42,25 & 41,23 & $-2,4$ \\
\hline 11 & 3204 & Materiales sintéticos y orgánicos para teñir & 29,72 & 37,84 & 27,3 \\
\hline 12 & 6206 & Blusas, shorts para mujeres y niñas & 24,94 & 36,63 & 46,9 \\
\hline 13 & 6204 & Vestidos, chaquetas, etc. para mujeres y niñas & 15,90 & 33,27 & 109,2 \\
\hline 14 & 2941 & Antibióticos & 28,00 & 33,04 & 18,0 \\
\hline 15 & 5205 & Hilos y filamentos de algodón & 20,77 & 32,92 & 58,5 \\
\hline \multicolumn{3}{|c|}{15 principales productos subtotal (A) } & 1228,14 & 1791,36 & 45,9 \\
\hline \multicolumn{3}{|c|}{ Total importado desde América Latina y el Caribe (B) } & 2160,70 & 2993,47 & 38,5 \\
\hline \multicolumn{3}{|c|}{ Participación los 15 principales productos en total ALC $(\mathrm{A}) /(\mathrm{B}) * 100(\%)$} & $\mathbf{5 6 , 8}$ & $\mathbf{5 9 , 8}$ & \\
\hline \multicolumn{3}{|c|}{ Total importado desde el mundo $(\mathrm{C})$} & 83535,94 & 103090,54 & 23,4 \\
\hline \multicolumn{3}{|c|}{ Participación de América Latina en el mundo $(\mathrm{A}) /(\mathrm{C}) * 100(\%)$} & 2,6 & 2,9 & \\
\hline
\end{tabular}

Fuente: Government of India, Ministry of Commerce \& Industry, Department of Commerce, http://dgft.delhi.nic.in/.

a sA: Sistema Armonizado de Designación y Codificación de Mercancías.

\section{China como eje del dinamismo del comercio entre países asiáticos}

A partir del marcado crecimiento de su economía, China se ha transformado en el eje del dinamismo comercial asiático. La importancia de Asia como proveedora de China es bien conocida: en el 2005, Japón, la provincia china de Taiwán, la República de Corea y los países de la ASEAN suministraron la mitad de las importaciones realizadas por China. Con estos países — sobre todo la República de Corea y Japón - China tiene un intercambio global deficitario, debido a que ellos son la principal fuente de bienes de capital e insumos intermedios para su producción manufacturera. Esta producción luego se exporta al resto de los socios comerciales, en particular los Estados Unidos y la Unión Europea, con los que China mantiene invariablemente los mayores superávit comerciales en manufacturas de baja y alta tecnología $\mathrm{y}$, en menor medida, en productos de tecnología media (CEPAL, 2005). De este modo, el déficit comercial de
China con Asia, que en el 2005 superó los 70.000 millones de dólares, se ha visto más que compensado por los cuantiosos y crecientes superávit comerciales con los Estados Unidos (114.000 millones de dólares) y con la Unión Europea (70.000 millones de dólares).

El comercio de la ASEAN con China totalizó 114.300 millones de dólares, equivalentes a $10,9 \%$ del comercio total de esta agrupación en el 2005. China ocupó el cuarto lugar entre los mayores socios comerciales de la AsEan, tras Japón, los Estados Unidos y la Unión Europea. De modo similar, la ASEAN alcanzó el quinto lugar entre los socios comerciales de China, después de los Estados Unidos, la Unión Europea, Japón y la Región Administrativa Especial de Hong Kong. Impulsan este dinamismo el sector de equipos electrónicos, y en menor grado, los sectores basados en los recursos naturales. Cuando esté plenamente en vigor el acuerdo comercial entre China y la ASEAN, el conjunto de todos estos países podría convertirse en un bloque comercial que superaría al grupo de países del Tratado de Libre Comercio de 
América del Norte en términos de comercio intrazonal (People's Daily Online, 2005).

Los exportadores latinoamericanos de productos primarios compiten fuertemente en el mercado chino con exportadores de otras regiones, particularmente aquellos de las economías de la ASEAN. Hoy China depende más de los países de la Asociación Latinoamericana de Integración (ALADI) que de los países de la ASEAN como fuente de suministro de productos primarios (cuadro 9). Sin embargo, con respecto a las manufacturas basadas en recursos naturales, la ASEAN duplica la participación de la ALADI en el mercado chino. Alrededor del $20 \%$ de las manufacturas de alta tecnología importadas por China proviene de los países de la ASEAN y más del $8 \%$ de las exportaciones chinas de productos de alta tecnología y más del $11 \%$ de las manufacturas chinas basadas en recursos naturales se dirigen a los países de la ASEAN. Estos porcentajes relativamente altos indican que existe una red de comercio intraindustrial entre China y la ASEAN, y que una parte importante de las materias primas y las manufacturas basadas en recursos naturales pertenecen a sectores en los cuales los países miembros de la ALADI enfrentan una severa competencia con los países asiáticos.

La fuerte competencia actual se confirma en el cuadro 10, que recoge las 30 principales categorías de productos importados por China desde América Latina y el Caribe en 2004 y detalla los cinco mayores proveedores de cada uno de esos 30 productos con su respectiva participación de mercado. Lo que salta a la vista es la importancia de muchos países asiáticos como proveedores de los mismos recursos naturales en los cuales América Latina tiene una apreciable ventaja comparativa en el mercado chino y en los cuales sigue especializándose. Pese a la marcada presencia de algunos países latinoamericanos entre los principales proveedores de productos primarios, se considera que la competencia entre los países latinoamericanos se intensificará y que la desviación de comercio podría afectar significativamente a América Latina si no se adoptan políticas activas en materia de acuerdos comerciales bilaterales o subregionales.

Además, como se desprende del cuadro 9, que muestra los porcentajes de participación de China e India en las corrientes de comercio con la ASEAN y la ALADI, India comienza a integrar la red de comercio intraindustrial asiática. Para India, los países de la ASEAN son un importante proveedor de bienes primarios y manufacturas basadas en recursos naturales, mucho más que los países de la ALADI. La participación de la ASEAN en las importaciones de manufacturas de India es relativamente alta. Aproximadamente el $16 \%$ de las importaciones indias de manufacturas de alta tecnología y casi el $8 \%$ de aquellas de tecnología mediana y baja provienen de los países vecinos integrantes de la ASEAN. La gravitación de los países de la ALADI como destino de las exportaciones de India es muy reducida.

El mercado indio ha sido poco explotado por América Latina y el Caribe. Además del crecimiento del sector de las tecnologías de información y telecomunicaciones, se observa el avance de otros sectores manufactureros, como la industria automotriz, la de productos electrónicos y la de equipos de transporte. Por otra parte, el Gobierno de India apoya a la industria farmacéutica — así como a la de biotecnología, que se encuentra en pleno desarrollo- con el propósito de aprovechar sus recursos humanos y biogenéticos.

\section{Tratados de libre comercio con China e India}

En el este de Asia se está constituyendo un nuevo orden comercial que se articula en torno a la economía china. Esta región, que se proyecta como un bloque en la economía internacional, está consolidando el proceso de integración que se inició en los años 1980, estimulado por la inversión intrarregional y el crecimiento del comercio intraindustrial. Un régimen comercial preferente, junto a una mayor convergencia de las normas sobre disciplinas comerciales, inversiones, servicios, estándares técnicos y fitosanitarios, facilitación del comercio y movilidad, entre otras materias, daría un impulso decisivo a la profundización de la integración regional. Una futura área de libre comercio que integrara a China, Japón y la República de Corea con la ASEAN y una posible ampliación de este esquema que incluyera a Australia, Nueva Zelandia e India, estimularía fuertemente el comercio intrarregional. Pero, sobre todo, tendría un efecto considerable en la geografía económica del Asia-Pacífico. Un área de libre comercio entre la ASEAN y China concentraría un PIB combinado de al menos 1,6 billones de dólares y, si se suma a Japón, de 5,5 billones de dólares, convirtiendo al este de Asia en un polo relevante frente a los Estados Unidos y Europa.

En los últimos años, China e India han negociado varios acuerdos comerciales. Al comienzo China estableció arreglos comerciales especiales con Hong Kong (región administrativa especial de China) y Macao, luego concluyó un Tratado de Libre Comercio (TLC) con Chile y un acuerdo de "cosecha temprana" con Pakistán, ${ }^{5}$ y

\footnotetext{
${ }^{5}$ Es decir, un acuerdo que comenzaba a rendir frutos aun antes de hallarse en pleno vigor.
} 
China e India: composición de su comercio con la ASEAN y la ALADI, 1990-2004a

(Participación porcentual en las corrientes de comercio de cada grupo de productos)

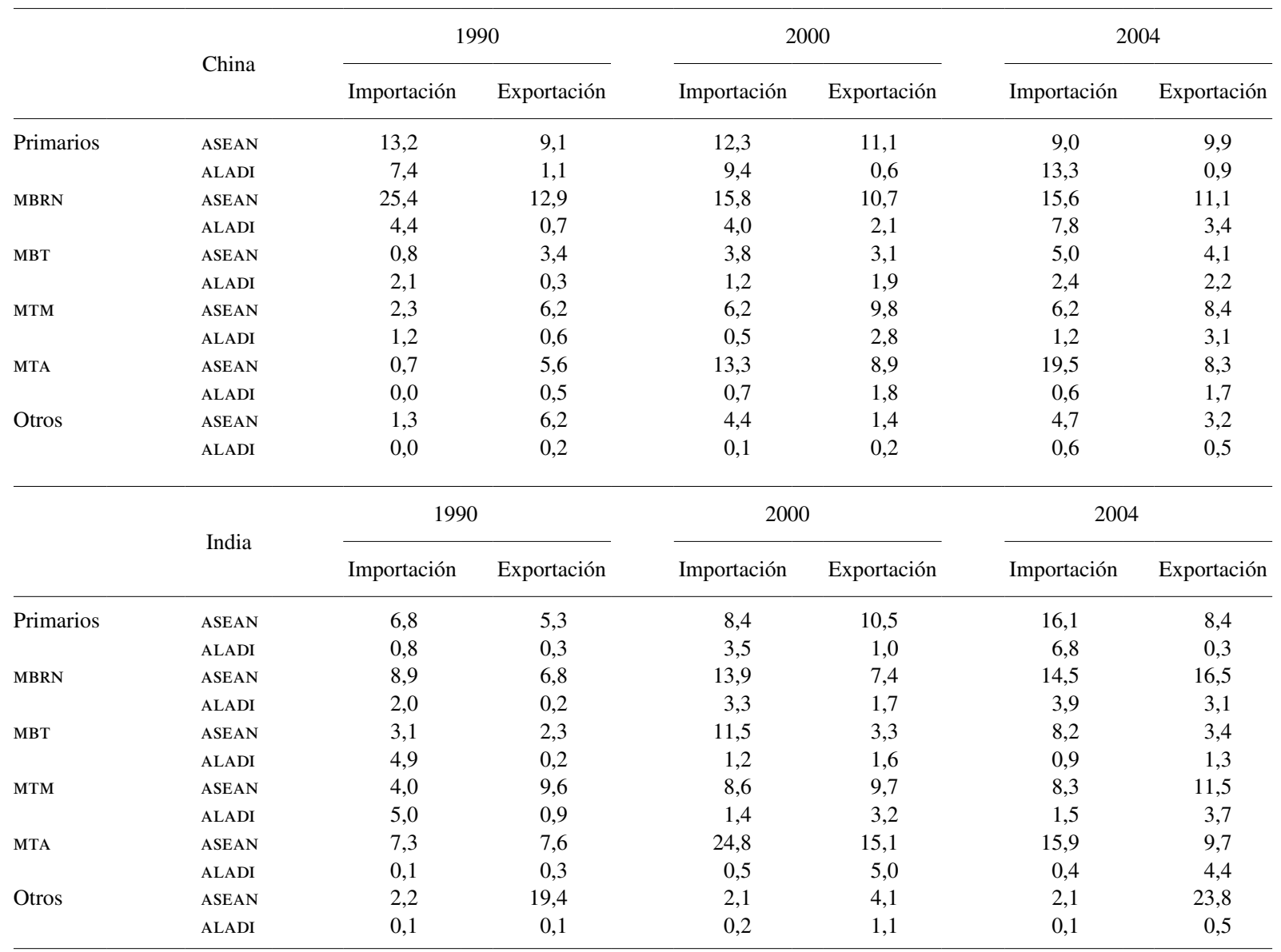

Fuente: elaboración propia con información de la Base de datos estadísticos sobre el comercio de mercaderías (COMTRADE).

a ASEAN: Asociación de Naciones del Asia Sudoriental. ALADI: Asociación Latinoamericana de Integración. Primarios: productos primarios. MBRN: manufacturas basadas en recursos naturales; MBT: manufacturas de baja tecnología; MTM: manufacturas de tecnología mediana. MTA: manufacturas de tecnología alta.

comenzó a reducir los aranceles comerciales que se aplicaban a los países de la ASEAN. China ha firmado o está negociando acuerdos de libre comercio con alrededor de 27 países (People's Daily Online, 2006). India también está creando una compleja red de acuerdos comerciales; ha celebrado ocho acuerdos de libre comercio, entre los cuales se cuentan los Acuerdos Parciales con Chile y el Mercosur, está negociando acuerdos con otros ocho grupos de países y estudia la posibilidad de llegar a acuerdos con diez más (cuadro 11). China ha firmado sendos acuerdos de protección de inversiones con Argentina, Barbados, Bolivia, Chile, Cuba, Ecuador, Jamaica, Perú y Uruguay, mientras tiene firmados sendos acuerdos de turismo con seis países latinoamericanos (Argentina, Brasil, Chile, Cuba, México y Perú) desde el 2003 (Gobierno de China, 2006).

La reciente tendencia hacia la consolidación de relaciones comerciales por la firma de acuerdos comerciales de distinta índole entre América Latina, por un lado, y el Asia-Pacífico, por otro, tiende a facilitar la posible incorporación de empresas latinoamericanas a cadenas asiáticas en torno a China e India. El acuerdo ya firmado entre Chile y China y el acuerdo suscrito entre India y el Mercosur son promisorios, pero requieren mayor profundización y cobertura. Aquel entre Chile y China, primer acuerdo comercial que China firma con un país 
CUADRO 10

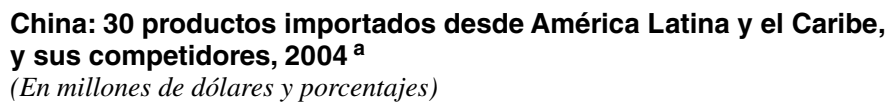

\begin{tabular}{|c|c|c|c|c|c|c|c|c|c|c|}
\hline \multirow{2}{*}{\multicolumn{2}{|c|}{$\begin{array}{c}\text { Código } \\
\text { CUCI, } \\
\text { Rev } 2\end{array}$}} & \multirow{2}{*}{$\begin{array}{c}\text { Descripción de los productos } \\
1\end{array}$} & \multirow{2}{*}{$\begin{array}{c}\text { Valor } \\
2\end{array}$} & \multirow{2}{*}{$\begin{array}{c}\begin{array}{c}\text { Mundo } \\
(\%)\end{array} \\
3\end{array}$} & \multicolumn{5}{|c|}{$\begin{array}{l}\text { Principales países proveedores } \\
\text { y porcentajes de las importaciones }\end{array}$} & \multirow{2}{*}{$\begin{array}{r}\text { Total } \\
5\end{array}$} \\
\hline & & & & & & & 4 & & & \\
\hline 1 & 222 & Semillas y frutas oleaginosas enteras o partidas & 2776 & 38,6 & USA & BRA & ARG & $\mathrm{CAN}$ & IND & 99,4 \\
\hline 2 & 682 & Cobre y sus aleaciones & 1822 & 23,6 & CHL & TWN & KOR & JPN & $\mathrm{Z} / \mathrm{F}^{\mathrm{b}}$ & 67,0 \\
\hline 3 & 287 & Minerales de metales comunes y sus concentrados & 1652 & 24,8 & AUS & CHL & PER & IND & USA & 61,4 \\
\hline 4 & 423 & Aceites fijos de origen vegetal, líquidos, brutos, refinados & 1350 & 75,2 & ARG & BRA & CAN & AUS & TWN & 99,1 \\
\hline 5 & 281 & Mineral de hierro y sus concentrados & 1242 & 9,8 & IND & AUS & BRA & ZAF & CAN & 88,6 \\
\hline 6 & 251 & Pulpa y desperdicios de papel & 611 & 11,5 & USA & CAN & IDN & RUS & BRA & 69,7 \\
\hline 7 & 081 & Piensos para animales (excepto cereales sin moler) & 544 & 57,3 & PER & USA & CHL & IND & RUS & 82,4 \\
\hline 8 & 333 & Aceites de petróleo crudos & 407 & 1,2 & AGO & SAU & $\mathrm{OMN}$ & IRN & RUS & 59,3 \\
\hline 9 & 611 & Cuero & 403 & 12,0 & TWN & KOR & ITA & $\mathrm{Z} / \mathrm{F}^{\mathrm{b}}$ & BRA & 65,9 \\
\hline 10 & 759 & Partes y accesorios (distintos de los estuches, tapas) & 256 & 1,7 & $\mathrm{Z} / \mathrm{F}^{\mathrm{b}}$ & JPN & TWN & KOR & THA & 78,5 \\
\hline 11 & 672 & Lingotes y otras formas primarias de hierro o acero & 242 & 3,8 & KOR & JPN & TWN & UKR & RUS & 65,3 \\
\hline 12 & 671 & Arrabio, fundición especular, hierro esponjoso, polvo & 229 & 20,8 & KAZ & VEN & RUS & AUS & BRA & 56,6 \\
\hline 13 & 248 & Madera trabajada y traviesas de madera & 165 & 11,7 & USA & IDN & THA & BRA & RUS & 63,6 \\
\hline 14 & 674 & Planos universales, chapas y planchas de hierro o acero & 156 & 1,3 & JPN & TWN & KOR & RUS & KAZ & 77,6 \\
\hline 15 & 288 & Desperdicios y desechos de metales & 143 & 4,0 & USA & JPN & HKG & BEL & AUS & 61,3 \\
\hline 16 & 713 & Motores de combustión interna, de émbolo y sus partes & 113 & 3,0 & JPN & DEU & KOR & USA & HUN & 79,8 \\
\hline 17 & 776 & Lámparas, tubos y válvulas electrónicas de cátodo frío & 104 & 0,1 & TWN & JPN & KOR & MYS & PHL & 72,2 \\
\hline 18 & 121 & Tabaco en bruto, residuos de tabaco & 102 & 43,9 & ZWE & BRA & USA & CAN & TUR & 99,0 \\
\hline 19 & 784 & Partes y accesorios n.e de los vehículos automotores & 102 & 1,4 & JPN & DEU & KOR & TWN & USA & 86,1 \\
\hline 20 & 651 & Hilados de fibras textiles & 62 & 1,5 & $\mathrm{Z} / \mathrm{F}^{\mathrm{b}}$ & TWN & KOR & PAK & JPN & 75,4 \\
\hline 21 & 263 & Algodón & 60 & 1,9 & USA & UZB & AUS & BFA & BEN & 77,8 \\
\hline 22 & 011 & Carnes y despojos comestibles de carnes & 60 & 12,6 & USA & CAN & DNK & BRA & NZL & 83,1 \\
\hline 23 & 583 & Productos de polimerización y copolimerización & 48 & 0,3 & TWN & KOR & JPN & USA & SGP & 66,2 \\
\hline 24 & 341 & Gas natural y artificial & 45 & 1,9 & SAU & ARE & AUS & KWT & THA & 78,0 \\
\hline 25 & 034 & Pescado fresco, refrigerado o congelado & 44 & 2,6 & RUS & USA & NOR & JPN & PRK & 75,1 \\
\hline 26 & 641 & Papel y cartón & 39 & 0,9 & USA & JPN & TWN & KOR & IDN & 53,3 \\
\hline 27 & 058 & Frutas en conserva y preparados de frutas & 38 & 35,1 & BRA & USA & ISR & SWE & THA & 64,6 \\
\hline 28 & 742 & Bombas para líquidos con o sin medidor & 36 & 2,2 & DEU & JPN & USA & KOR & ITA & 69,6 \\
\hline 29 & 036 & Crustáceos y moluscos pelados o sin pelar & 36 & 5,6 & PRK & CAN & KOR & PER & USA & 62,0 \\
\hline \multirow[t]{3}{*}{30} & 273 & Piedra, arena y grava & 35 & 4,7 & IND & EGY & TUR & BRA & ESP & 62,0 \\
\hline & & Otros productos & 858 & & & & & & & \\
\hline & & Comercio total & 13780 & & & & & & & \\
\hline
\end{tabular}

Fuente: base de datos estadísticos sobre el comercio de mercaderías (COMTRADE), de la División de Estadística de las Naciones Unidas.

a La columna 1 presenta los 30 principales productos importados por China desde América Latina y el Caribe, basándose en el valor de las importaciones en 2004. La columna 2 detalla el valor de las importaciones de estos productos en 2004. La columna 3 corresponde a la proporción del producto importado desde América Latina y el Caribe en las importaciones totales del producto desde el mundo. La columna 4 enumera los cinco principales proveedores del producto. La columna 5 presenta la proporción de estos cinco países en el valor total de las importaciones.

b Zonas francas. 
En implementación o firmado
Acuerdo marco (AM) firmado o en negociación
Propuesta/en etapa de estudio

\section{CHINA}

- Área de Libre Comercio ASEAN-China (en implementación)

- Acuerdo Comercial Asia-Pacífico (en implementación) ${ }^{\mathrm{a}}$

- Tratado de Libre Comercio (TLC) Chile-China (en implementación)

- Acuerdo de Asociación Económica más Estrecha China-Hong Kong (en implementación)

- Acuerdo de Asociación Económica más Estrecha China continental-Macao (en implementación)

- TLC China-Pakistán (firmado)

- TLC China-Tailandia (en implementación)
- TLC Nueva Zelandia-China (AM firmado, TLC en negociación)

- TLC China-Australia (AM firmado, TLC en negociación)

- TLC China-Consejo de Cooperación del Golfo (en negociación) ${ }^{\mathrm{b}}$ TLC ChinaIslandia (en negociación)

- TlC China-Singapur (en negociación)

- China - Unión Aduanera Sudafricana

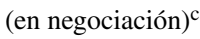

- Acuerdo de comercio regional China-India

- Área de libre comercio del Asia oriental

- TlC China-Japón-Rep. de Corea

- tlc China-Rep. de Corea

- TlC China-Perú

- TLC China Sudáfrica

- TLC de la Organización de cooperación de Shanghai

\section{7}

6

\section{INDIA}

- Acuerdo Comercial del Asia-Pacífico (en implementación) ${ }^{\mathrm{a}}$

- Acuerdo Preferencial de Comercio India-Afganistán(firmado)

- Acuerdo Preferencial de Comercio India-Chile (firmado)

- Acuerdo Preferencial de Comercio India-Mercosur (firmado)

- Acuerdo Amplio de Cooperación Económica India-Singapur (en implementación)

- TLC India -Sri-Lanka (en implementación)

- Tratado de comercio India-Nepal (en implementación)

- $\quad$ TLC del Sur de Asia (en implementación) ${ }^{\mathrm{d}}$
- Área de comercio e inversión regionales ASEAN-India (am firmado, TLC en negociación)

- Iniciativa de la Bahía de Bengala para la Cooperación Multisectorial, Técnica y Económica (AM firmado, TLC en negociación)

- Acuerdo preferencial de de comercio India-Egipto (en negociación)

- TLC India-Consejo de Cooperación del Golfo (AM firmado, TLC en negociación $)^{b}$

- Acuerdo amplio de cooperación económica y asociación entre India y la Rep. de Corea)

- Acuerdo amplio de cooperación económica y asociación India-Mauricio (en negociación)

- Acuerdo de Comercio Preferencial entre India y la Unión Aduanera Sudafricana (AM firmado, TLC en negociación) ${ }^{\mathrm{c}}$

- TLC India -Tailandia (AM firmado, TLC en negociación)
- Acuerdo regional de comercio China-India

- TLC India-Australia

- Acuerdo preferencial de comercio India-Colombia

- TLC India-Unión Europea

- Acuerdo amplio de cooperación económica India-Indonesia

- Acuerdo de comercio preferencial India-Israel

- Acuerdo amplio de asociación económica India-Rep. de Corea

- Acuerdo preferencial de comercio India-Uruguay

- Acuerdo preferencial de comercio India-Venezuela

- Tratado de comercio India-Nepal

- Acuerdo amplio de cooperación económica Malasia-India

Fuente: elaboración propia, sobre la base de People's Daily Online (2005), CESPAP (2005), Asian Development Bank, Free Trade Agreement Database for Asia, http://aric.adb.org/; NIC (s/f) y DIRECON (s/f). Las denominaciones de los acuerdos y tratados que carecen de nombres oficiales en español corresponden a traducciones del inglés.

a Inicialmente, los cinco Estados participantes en el Acuerdo eran Bangladesh, India, la República de Corea, la República Democrática Popular Lao y Sri Lanka. La Comisión Económica y Social para Asia y el Pacífico (CESPAP) de las Naciones Unidas actúa como Secretaría del Acuerdo.

b Los miembros son Arabia Saudita, Bahrein, los Emiratos Árabes Unidos, Kuwait, Omán y Qatar.

c Los miembros son Botswana, Lesotho, Namibia, Sudáfrica y Swazilandia.

d Se refiere a Bangladesh, Bhután, India, Maldivas, Nepal, Pakistán y Sri Lanka. 
occidental, se considera un puente entre América del Sur y el Asia-Pacífico. A los acuerdos mencionados se suman otras iniciativas de varios países asiáticos y latinoamericanos ribereños del Pacífico, como el Tratado de Libre Comercio entre Chile y la República de Corea, que fue el primer TLC transpacífico; el Acuerdo Estratégico Transpacífico de Asociación Económica entre Chile y Nueva Zelandia, Singapur y Brunei Darussalam ya firmado; varias iniciativas planteadas por Perú (un TLC con Tailandia cuyas negociaciones se concluyeron en 2005 y otros posibles con Singapur, China e India), y el TLC entre Panamá y Singapur. Además, Chile acaba de concluir la negociación de un TLC con Japón y está en negociación con Tailandia y Malasia. Este conjunto de iniciativas muestra serios intentos de los países latinoamericanos por abordar con criterios más estratégicos la relación con China y con el resto del Asia-Pacifico.

\section{Implicancias para América Latina y el Caribe de un tratado de libre comercio de alcance regional en Asia}

La conformación de un área de libre comercio en Asia que incluya China, la República de Corea y Japón (y que en el futuro pueda incluir a India como socio comercial) representa un desafío para América Latina y el Caribe, porque la integración en Asia tiene un cariz más intrarregional, con una mayor participación de las exportaciones intrarregionales en el esquema de preferencias arancelarias. Como se señaló más atrás, las importaciones provenientes de la región latinoamericana y caribeña permanecen concentradas en bienes primarios y recursos naturales, en tanto que las importaciones provenientes de la ASEAN se apoyan más en sectores de alta tecnología, como los de la información y las comunicaciones, cuyos aranceles han bajado considerablemente en los últimos años.

Por lo tanto, la desventaja de América Latina y el Caribe en los mercados chinos de estos rubros frente a la competencia de la ASEAN se atenuaría si los países de la región firmaran acuerdos de libre comercio con los países de esa asociación. En efecto, la competencia más severa que enfrentarían los países de América Latina y el Caribe se daría en los sectores de productos primarios y de manufacturas basadas en recursos naturales, en los cuales los países de la ASEAN mantienen ventajas comparativas de producción si permanecen altos los aranceles efectivos (cuadro 12). Los aranceles que aplican los países de la ASEAN, China, Japón y la República de Corea (ASEAN+3) a los productos agrícolas, a los textiles $\mathrm{y}$ prendas de vestir $\mathrm{y}$ a algunos sectores de maquinaria siguen siendo elevados, de manera que en el ámbito del acuerdo ASEAN +3 o del acuerdo de la ASEAN con cada uno de los tres países indicados, o incluso del acuerdo China-AsEAn o el acuerdo AsEAN-India, una rebaja de estos aranceles favorecería a los países de la ASEAN, a costa de los países de América Latina y el Caribe.

Estos nuevos acuerdos contemplados por la ASEAN con varios socios comerciales fuera de su propia agrupación son vistos como una segunda ola de tratados de comercio preferenciales, posteriores a la implementación del Proyecto Común de Aranceles Preferenciales Efectivos en el ámbito del Área de Libre Comercio de la Asociación de Naciones del Asia Sudoriental (AFTA), que se aprobó en 1992 y entró en vigor en 1993. Su objetivo principal es integrar las economías de la ASEAN en una única región productiva, capitalizando así un mercado amplio de 500 millones de habitantes.

\section{IV}

\section{Conclusiones y recomendaciones}

Por su importancia económica, estratégica y demográfica, China e India se destacan entre los países de Asia. En el ámbito económico estos países asiáticos, en especial el primero, han sido no solo un factor clave de los cambios significativos ocurridos en el nivel y la estructura de la demanda mundial, sino también una fuente importante de recursos financieros para mantener los equilibrios internacionales. Sin embargo, las relaciones entre América Latina y el Caribe y los dos países señalados están en sus inicios. En el caso de China se han dinamizado recientemente, sobre todo por el interés chino de asegurar el acceso a los recursos naturales de América del Sur.

Hasta ahora los intercambios de América del Sur con China e India se han centrado en la exportación a esos dos países de productos basados en recursos naturales, en tanto que las adquisiciones de la región se han orientado hacia manufacturas de baja, mediana 


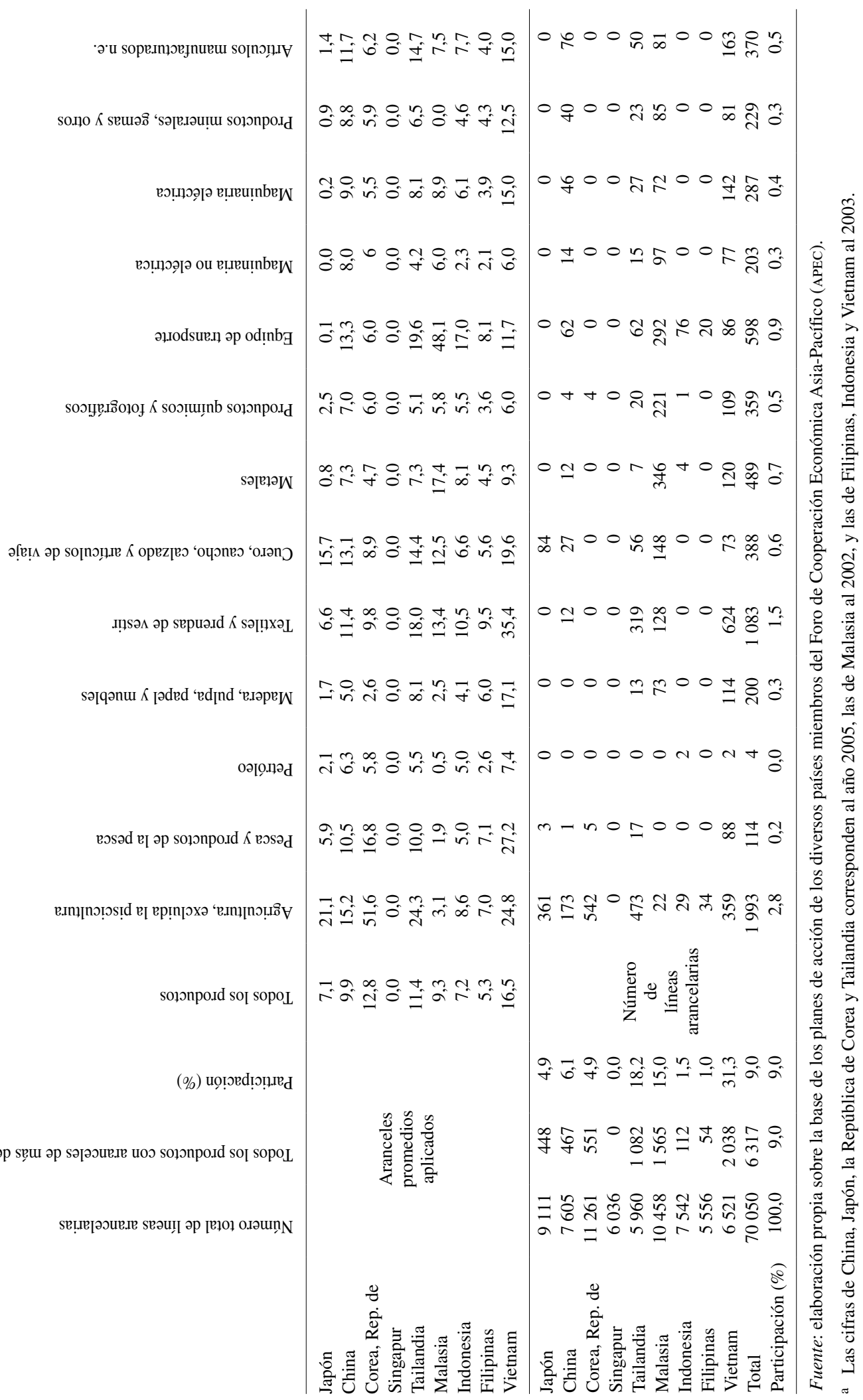


e incluso alta tecnología. China se ha transformado en uno de los principales destinos de las exportaciones de los países asiáticos, los que se han ido especializando paulatinamente y han dejado de ser solamente proveedores de manufacturas basadas en recursos naturales para transformarse en oferentes de insumos más complejos.

Dado que el comercio entre China y América del Sur se caracteriza por ser interindustrial, resta a la región lograr que sus empresas se asocien al éxito de las asiáticas, incorporándose a las cadenas de abastecimiento de las unidades de producción con insumos más elaborados y de nivel tecnológico más alto. Tal vez lo mejor sea partir por alianzas en torno a cadenas, que permitan una mayor elaboración de productos basados en los recursos naturales que actualmente se exportan al Asia. Para esta subregión es importante valorizar los recursos naturales, promoviendo contratos de largo plazo, acuerdos de inversión y alianzas tecnológicas en este sector, así como la constitución en Asia de aglomeraciones productivas estratégicas entre países, empresas y ciertas zonas geográficas. Es deseable también forjar alianzas estratégicas que permitan elevar el valor agregado en toda la cadena de producción y de comercialización, así como gestar alianzas tecnológicas de beneficio mutuo (por ejemplo, para aplicar los avances de la biotecnología a la producción agroindustrial, minera, forestal y piscícola).

Respecto a las relaciones estratégicas de México y Centroamérica con China, es preciso desplegar esfuerzos para que esa subregión se incorpore en el proceso regional de integración productiva impulsada por mercados asiáticos en los que China desempaña un papel cada vez más decisivo. La posibilidad existe, entre otras razones, por las ventajas logísticas y de cercanía geográfica que la subregión tiene respecto del mercado estadounidense. Este dato pesa en las estrategias globales de al menos China, Japón, la República de Corea y Singapur. Por otra parte, un comercio intraindustrial más intenso entre China, por un lado, y México y América Central, por otro, brindaría a esta subregión nuevas rutas de acceso al mercado chino, propiciaría la incorporación de nuevas tecnologías y mejoraría las habilidades de los trabajadores y las técnicas de gestión empresarial.
Pese a la alta presencia de algunos países latinoamericanos entre los principales proveedores de productos primarios, es probable que en estos rubros la competencia entre los países asiáticos y los sudamericanos se intensifique y que la desviación de comercio que afecte a América Latina y el Caribe sea significativa, si no se adoptan políticas activas en materia de acuerdos de comercio bilaterales o subregionales. Estos acuerdos tendrían consecuencias positivas para dicha región, por su impacto en las corrientes internacionales de inversión extranjera directa y por la creación de comercio que habría en los rubros en que sus exportaciones hacia China e India enfrentan actualmente una fuerte competencia de las economías del este de Asia.

Asimismo, urge que los países de la región aprovechen el dinamismo actual de China e India y los nuevos vínculos que con ellos se van gestando para avanzar en innovación y competitividad, un eslabón débil en la experiencia regional latinoamericana. Para ello habría que fortalecer los nexos entre comercio e inversiones, así como los eslabonamientos productivos y tecnológicos. China e India ofrecen inversiones (sobre todo en infraestructura, tecnologías de la información y las comunicaciones, y energía) que pueden complementar la financiación de emprendimientos importantes en estas áreas. Surge aquí un desafío interesante, que es el de identificar los proyectos de infraestructura, de energía y de investigación y desarrollo en los cuales esa inversión china o india sea más necesaria, para acelerar su puesta en práctica. Esto no sólo permitiría reforzar el vínculo con China y con el Asia-Pacífico tendiente a la facilitación del comercio y de las inversiones, sino que también generaría externalidades que favorecerían el propio proceso de integración subregional, sea en América del Sur o en México-Centro América. En este sentido, es posible vincular esa asociación estratégica con China e India con el aggiornamento de la integración regional, mediante mercados unificados, normas cada vez más comunes y mayor certidumbre jurídica. No existe una "muralla china" entre el reforzamiento de los vínculos económicos con el Asia-Pacífico y la actualización de la integración regional. Al contrario, con las políticas adecuadas y con voluntad política de ambos lados, es posible construir una complementariedad dinámica entre ambas opciones estratégicas. 


\begin{tabular}{|c|c|c|c|c|c|}
\hline Códigos & Países & Códigos & Países & Códigos & Países \\
\hline AGO & Angola & GBR & Reino Unido & NZL & Nueva Zelandia \\
\hline ARE & Unión Emiratos Árabes & GTM & Guatemala & OMN & Omán \\
\hline ARG & Argentina & HKG & Hong Kong (RAE) & PER & Perú \\
\hline AUS & Australia & HND & Honduras & PHL & Filipinas \\
\hline BEL & Bélgica & HUN & Hungría & PRK & Rep. Dem. Corea \\
\hline BEN & Benin & IDN & Indonesia & RUS & Fed. Rusa \\
\hline BGD & Bangladesh & IND & India & SAU & Arabia Saudita \\
\hline BFA & Burkina Faso & IRL & Irlanda & SGP & Singapur \\
\hline BRA & Brasil & IRN & Rep. Islámica de Irán & SLV & El Salvador \\
\hline CAN & Canadá & ISR & Israel & SWE & Suecia \\
\hline CHL & Chile & ITA & Italia & THA & Tailandia \\
\hline $\mathrm{CHN}$ & China & JPN & Japón & TUR & Turquía \\
\hline COL & Colombia & $\mathrm{KAZ}$ & Kazajstán & TWN & Prov. china de Taiwán \\
\hline CRL & Costa Rica & KOR & Rep. de Corea & UKR & Ucrania \\
\hline DEU & Alemania & KWT & Kuwait & USA & Estados Unidos \\
\hline DNK & Dinamarca & MEX & México & UZB & Uzbekistán \\
\hline DOM & Rep. Dominicana & MYS & Malasia & VEN & Rep. Bol. de Venezuela \\
\hline ECU & Ecuador & NGA & Nigeria & VNM & Vietnam \\
\hline ESP & España & NLD & Países Bajos & $\mathrm{ZAF}$ & Sudáfrica \\
\hline $\mathrm{F} / \mathrm{Z}$ & Zonas francas & NOR & Noruega & & \\
\hline
\end{tabular}

Fuente: base de datos estadísticos sobre el comercio internacional de mercaderías (COMTRADE) de la División de Estadística de las Naciones Unidas.

\section{Bibliografía}

Asian Development Bank, Free Trade Agreement Database for Asia, http://aric.adb.org/

Banco Mundial (varios años): World Economic Indicators, Washington, D.C.

Branstetter, L. y N. Lardy (2006): China's Embrace of Globalization, NBER Working Paper Series, $N^{\circ} 12373$, Cambridge, Massachusetts. Disponible en http://www.nber.org/ papers/w12373.

CePal (Comisión Económica para América Latina y el Caribe) (2005): Panorama de la inserción internacional de América Latina y el Caribe, 2004. Tendencias 2005 (LC/G.2283-P), Santiago de Chile, agosto. Publicación de las Naciones Unidas, $\mathrm{N}^{\mathrm{o}}$ de venta: S.05.II.G.117.

(2006): Panorama de la inserción internacional de América Latina y el Caribe, 2005-2006 (LC/G.2313-P), Santiago de Chile, agosto. Publicación de las Naciones Unidas, $\mathrm{N}^{\circ}$ de venta: S.06.II.G.67.

Cespap (Comisión Económica y Social para Asia y el Pacífico) (2005): Asia-Pacific Preferential Trade and Investment Agreements Database (APTIADA), Bangkok, Banco Asiático de Desarrollo.

DiRECON (Dirección General de Relaciones Económicas Internacionales, Chile) (s/f): http://www.DIRECON.cl/documentos/India2/ antecedentes_generales_india.pdf.

Dussel Peters, E. (2005): Economic Opportunities and Challenges Posed by China for Mexico and Central America, Studies, $N^{\circ} 8$, Bonn, Deutsche Institut fur Entwicklungspolitik.
FAO (Organización de las Naciones Unidas para la Agricultura y la Alimentación) (2004): El estado de los mercados de productos básicos agrícolas, Roma.

FMI (Fondo Monetario Internacional) (2006a): World Economic Outlook, Washington, D.C., Direction of Trade Statistics, abril. (2006b): World Economic Outlook, Washington, D.C., Direction of Trade Statistics, septiembre.

Gobierno de China (2006): China, Latin America forge closer links for win-win end. Disponible en http://www.gov.cn/misc/2006-10/06/ content_405906.htm.

Gobierno de India (2006): Economic Survey 2005-2006. Disponible en http://indiabudget.nic.in

India, Ministerio de Comercio e Industria (2006): FDI inflows into India, Nota de prensa, Departamento de comercio, 11 de mayo.

International Iron and Steel Institute (2005): World Steel in Figures 2005. Disponible en http://www.worldsteel.org/?action=publi cationdetail\&id=54

ISSB Monthly World I\&S Review (2005): Disponible en http://www. steelonthenet.com/production.html.

JETRO (Japan External Trade Organization) (2006): JETRO White Paper on Trade and Investment 2006, Tokio.

NIC (National Informatics Center) (s/f): India's trade: business opportunities. Disponible en http://www.indiainbusiness. nic. in/trade-india/fta-rta.htm.

OMC (Organización Mundial del Comercio) (2006): Perfiles comerciales 2006, Ginebra. 
People's Daily Online (2005): China-ASEAN FTA to be one of world's three pillars. Disponible en http://www.bilaterals.org/article. php3?id article $=2674$

(2006): China accelerates pace on FTA establishment in past five years. Disponible en http://english.people.com.cn/200601/29/ print20060129_239189.html.

PNUD (Programa de las Naciones Unidas para el Desarrollo) (2006): Asia-Pacific Human Development Report 2006, Colombo, Sri Lanka, Macmillan.

The Economist Intelligence Unit (2005): BP Statistical Review of World Energy, Londres, junio. Disponible en http://www.bp.com
The Economist Intelligence Unit (2006): Global outlook, Londres, abril.

UNCTAD (Conferencia de las Naciones Unidas sobre Comercio y Desarrollo) (2003): Commodity Yearbook 2003, Ginebra, Naciones Unidas. Publicación de las Naciones Unidas, $\mathrm{N}^{\circ}$ de venta: E/F.03.II.D.25.

(2005): Informe sobre el comercio y el desarrollo, 2005, UNCTAD/TDR/2005, Ginebra. Publicación de las Naciones Unidas, $\mathrm{N}^{\circ}$ de venta: E.05.II.D.13.

World Bureau of Metal Statistics (2005): World Metal Statistics Yearbook, 2005, Londres. 